\title{
Neuroprotective Actions of Estradiol and Novel Estrogen Analogs in Ischemia: Translational Implications
}

\author{
Anne M. Etgen ${ }^{a, b}$, Teresa Jover-Mengual ${ }^{c}$, and R. Suzanne Zukina \\ Anne M. Etgen: anne.etgen@einstein.yu.edu; Teresa Jover-Mengual: teresa.jover@uv.es; R. Suzanne Zukin: \\ suzanne.zukin@einstein.yu.edu \\ ${ }^{a}$ Dominick P. Purpura Department of Neuroscience, Albert Einstein College of Medicine, 1300 \\ Morris Park Avenue, Bronx, NY 10461 USA \\ ${ }^{b}$ Department of Psychiatry \& Behavioral Sciences, Albert Einstein College of Medicine, 1300 \\ Morris Park Avenue, Bronx, NY 10461 USA \\ 'Departamento de Fisiología, Facultad de Farmacia, Universidad de Valencia, Campus de \\ Burjassot, Avda. Vicent Andrés Estellés, s/n, 46100 Burjassot, Valencia SPAIN
}

\begin{abstract}
This review highlights our investigations into the neuroprotective efficacy of estradiol and other estrogenic agents in a clinically relevant animal model of transient global ischemia, which causes selective, delayed death of hippocampal CA1 neurons and associated cognitive deficits. We find that estradiol rescues a significant number of CA1 pyramidal neurons that would otherwise die in response to global ischemia, and this is true when hormone is provided as a long-term pretreatment at physiological doses or as an acute treatment at the time of reperfusion. In addition to enhancing neuronal survival, both forms of estradiol treatment induce measurable cognitive benefit in young animals. Moreover, estradiol and estrogen analogs that do not bind classical nuclear estrogen receptors retain their neuroprotective efficacy in middle-aged females deprived of ovarian hormones for a prolonged duration ( 8 weeks). Thus, non-feminizing estrogens may represent a new therapeutic approach for treating the neuronal damage associated with global ischemia.
\end{abstract}

\section{Keywords}

stroke; global ischemia; neuroprotection; estradiol; hippocampus; estrogen receptor; insulin-like growth factor-1; GPR30; apoptosis; CREB

\section{Introduction}

Stroke is the third leading cause of death in the United States and the primary cause of disabilities in adults $[1 ; 2 ; 3]$. Of the 600,000 new victims each year, $30 \%$ die and another nearly $30 \%$ become severely and permanently disabled. Transient global ischemia arises as a consequence of cardiac arrest, cardiac surgery, profuse bleeding, near-drowning and carbon

\footnotetext{
(C) 2010 Elsevier Inc. All rights reserved.

Corrresponding author: Anne M. Etgen, Ph.D., Professor, D.P. Purpura Dept. Neuroscience, F113, Albert Einstein College of Medicine, 1300 Morris Park Ave., Bronx, NY 10461 USA, Phone: 718-430-3662, Fax: 718-430-8654, anne.etgen@einstein.yu.edu.

Publisher's Disclaimer: This is a PDF file of an unedited manuscript that has been accepted for publication. As a service to our customers we are providing this early version of the manuscript. The manuscript will undergo copyediting, typesetting, and review of the resulting proof before it is published in its final citable form. Please note that during the production process errors may be discovered which could affect the content, and all legal disclaimers that apply to the journal pertain.
} 
monoxide poisoning and affects $\sim 200,000$ Americans each year [1;2;3]. Transient global ischemia causes selective, delayed death of hippocampal CA1 neurons in humans and can produce serious neurologic sequellae, of which cognitive deficits are most prominent. There are still remarkably few safe and effective treatments to reduce the neuronal cell death and cognitive dysfunction associated with ischemia. It is now well established that endogenous and exogenous estrogens exert profound neuroprotective effects in animal models of focal (stroke) and global ischemia $[4 ; 5 ; 6 ; 7 ; 8 ; 9 ; 10 ; 11 ; 12 ; 13 ; 14]$. Dietary intake of phytoestrogens (plant-derived estrogens) can also improve outcomes after focal $[15 ; 16]$ and global ischemia in rats [17]. In cultured neurons, estrogens can reduce cell death induced by excitotoxins (e.g., glutamate), oxidative stress, $\beta$-amyloid, and serum deprivation $[18 ; 19 ; 20 ; 21 ; 22 ; 23 ; 24 ; 25]$. Moreover, estrogens are reported to reduce ischemia-induced damage to tissues such as kidney and heart and to reduce apoptosis in vascular smooth muscle $[26 ; 27 ; 28 ; 29 ; 30]$. A multicenter study of postmenopausal women also reported that longer lifetime exposure to ovarian estrogens may protect against ischemic stroke [31].Thus, estrogens hold great promise as potential therapeutic agents in treatment of ischemia. Yet, the clinical use of estradiol and related estrogens in menopausal women remains controversial. Large clinical trials such as the Women's Health Initiative (WHI) and the Heart and Estrogen/Progestin Replacement Study (HERS) called into question the ability of hormone treatment to reduce the occurrence or incidence of cardiovascular disease, stroke and dementia in postmenopausal women $[32 ; 33 ; 34 ; 35 ; 36]$. Another clinical trial, the Women Estrogen Stroke Trial (WEST), reported no beneficial effects of estradiol on stroke incidence; indeed postmenopausal women with estradiol treatment had an increased risk of stroke and worse neurological outcomes [37]. The current situation underscores the importance of animal studies to address unanswered questions regarding the efficacy of hormone treatment to reduce the extent of ischemia-induced neuronal damage and associated cognitive impairment.

Our laboratories initiated studies on the neuroprotective actions of the most abundant ovarian estrogen, 17 $\beta$-estradiol (hereafter referred to as estradiol), in animal models of global ischemia about 10 years ago. Global ischemia induced by four vessel occlusion (4VO; see Figure 1A) in rats is possibly the best established animal model of global ischemia [38]. A brief episode (10 min) induces selective death of CA1 pyramidal neurons and, as in humans, results in delayed onset of cognitive neurological deficits [39]. Inhibitory interneurons of the CA1 and virtually all neurons in the nearby CA 2 or transition zone, CA3 and dentate gyrus survive. With the exception of a few scattered hilar neurons and/or pyramidal neurons in cortex, other neurons do not exhibit cell death. Although the 4-VO model virtually ablates hippocampal CA1 pyramidal neurons by 7 days, the onset of histologically detectable neuronal death is delayed by $2-3$ days [40], enabling molecular studies of cells "destined to die" under conditions in which cell loss is not yet evident. This model is also clinically relevant to global ischemia associated with cardiac arrest in humans and offers the ability to compare changes in gene expression in neurons of the vulnerable CA1 with those of the resistant CA3. Moreover, because blood circulation to the cranium is completely blocked (rather than reduced by hypotension), monitoring of blood flow is not necessary. It has not been possible to exploit the power of transgenic mice to study global ischemia, because it is difficult to achieve delayed, selective hippocampal cell death in most mouse strains.

At the time we began our work, there was limited evidence that estradiol reduced CA1 neuronal death and ameliorated the cognitive deficits associated with ischemic cell death after global ischemia [41;42;43;44]. As described in the following review, we have now explored a number of clinically relevant issues, including the timing and route of hormone administration, the cellular and molecular mechanisms of estradiol's neuroprotective 
actions, the degree to which neuronal preservation correlates with functional outcomes, and the effects of age and prolonged hormone withdrawal.

\section{Pretreatment with estradiol in young animals}

We first examined the impact of estradiol administration on global ischemia induced neuronal death in young adult male gerbils. The two vessel occlusion model in gerbils affords a clinically relevant surgical model of global ischemia which is relatively simple and requires a shorter duration of occlusion $(5 \mathrm{~min})$ relative to rats. To mimic the effect of long term estradiol therapy in humans, we delivered estradiol to gerbils via subcutaneous, timedrelease pellets for 2 weeks prior to induction of ischemia. The pellets remain in place during and after ischemia until the animals are killed for histological evaluation 7 days postischemia. We found that estradiol administered at levels used for hormone therapy in postmenopausal women intervenes in apoptotic death cascades (e.g., elevation of caspase-3 activity) in male gerbils and affords robust protection against ischemia-induced cell death in hippocampal CA1 (Figure 2) [45]. We subsequently showed that 2-week pretreatment with physiological levels of estradiol (30-60 pg/ml in rats, the range of circulating levels at proestrus) attenuates ischemia-induced CA1 cell death in young, ovariectomized (OVX) female gerbils and rats [46;47] (Figure 2). Thus, in agreement with others (see Introduction), estradiol pretreatment is neuroprotective in young female and male rats and gerbils. Because pharmacological agents and antibodies used to explore the cellular and molecular basis of estrogen action and of cell survival pathways have not always been validated for use in gerbils, almost all of the remaining studies we carried out involved OVX female rats.

\subsection{Cellular and molecular mediators of estradiol protection}

Estrogens produce their cellular actions, at least in part, by binding the classical estrogen receptors $\mathrm{ER} \alpha$ and $-\beta$, which were traditionally thought to function as ligand-activated transcription factors (for reviews see [48;49]). Ligand activation of ER $\alpha$ and $-\beta$ leads to formation of a receptor dimer with high affinity for specific DNA sequences (estrogen response elements) within the promoters of target genes. The ER dimer can also interact with other DNA elements to regulate gene transcription, such as AP1 sites (known as the "tethered" mechanism see [50;51;52]), and associate with coregulators that function as transcriptional enhancers or repressors (see [53;54]). In addition to these genomic actions, estrogens act via extranuclear signaling pathways to indirectly affect transcription of other target genes [55;56]. Studies involving ER $\alpha$ and ER $\beta$ selective agonists and mice with targeted deletions of $E R \alpha$ and $E R \beta$ indicate that $E R \alpha$ is critical for estradiol protection against neuronal injury in animals undergoing middle cerebral artery occlusion (MCAO; see Figure 1B), a focal ischemia model and clinically-relevant model of ischemic stroke in humans [57]. This conclusion was confirmed in rats using pharmacological agents that selectively target ER $\alpha$ and ER $\beta$ [58]. More recently, studies of mice in which ER $\alpha$ is knocked out in specific cell types indicate that neuronal but not microglial ER $\alpha$ is required for neuroprotection after MCAO in both male and female animals [59].

To evaluate the role of classical ERs as mediators of estradiol neuroprotection in a model of global ischemia, we delivered the broad-spectrum ER antagonist ICI 182,780, a competitive antagonist of estradiol binding to both classical ER isoforms, intracerebroventricularly (icv) during the early post-ischemic period (at 0 and $12 \mathrm{~h}$ after reperfusion). Estradiol pellets were implanted 2 weeks prior to ischemia and remained on board until rats were killed for histological evaluation at 7 days after ischemia [47]. The classical ER antagonist ICI 182,780 abrogated estradiol-elicited neuroprotection (Figure 3B), consistent with a role for classical ERs. To evaluate the role of ER $\alpha$ vs. ER $\beta$, we administered subtype-selective agonists daily for 2 weeks before and 7 days after ischemia. Both propyl pyrazole triol (PPT, ER $\alpha$-selective) and WAY 200070-3 (ER $\beta$-selective) promoted survival of nearly all CA1 
pyramidal neurons in approximately $50 \%$ of the animals (Figure 3A), suggesting that estradiol can act via $E R \alpha$ and $E R \beta$ to protect CA1 neurons from global ischemia-induced death [47]. Studies from other investigators also implicate both ER subtypes in the neuroprotective actions of estradiol when administered as a pretreatment for global ischemia [7;60;61]. Therefore, the cellular mediators of estradiol's neuroprotective actions appear to differ for focal (ER $\alpha)$ and global ischemia (ER $\alpha$ and $E R \beta)$. Interestingly, both estradiol administration and global ischemia markedly and selectively increased the abundance of ER $\alpha$ protein in CA1, as assessed by Western blot analysis [47]. Similar increases in ER $\alpha$ expression in cortical neurons have been reported after MCAO [62], suggesting that increased expression of $\mathrm{ER} \alpha$ may be a common response to brain ischemia.

We have also examined a role for the endogenous growth factor, insulin-like growth factor-1 (IGF1), as an essential co-mediator of estradiol's neuroprotective actions. Both endogenous and exogenous IGF1 act in the early post-ischemic period to reduce apoptotic neuronal cell death (see [63]) and to promote vascular remodeling [64] after hypoxia-ischemia.

Considerable evidence implicates crosstalk between ER (primarily ER $\alpha$ ) and IGF1 signaling in the cellular actions of estradiol in the brain [12]. The physiological relevance of these interactions is underscored by the observation that activation of brain IGF1 receptors is critical to estrogen-dependent reproductive behaviors, neuroendocrine responses [65;66;67;68;69], synaptic remodeling, neuronal differentiation and neuronal survival [12]. To examine a possible role for IGF1 receptor activation in estradiol protection of CA1 neurons, we administered the highly selective and potent IGF1 receptor antagonist referred to as JB-1. JB-1 is a peptide analogue of IGF1 that mimics the recognition motif (" $\mathrm{D}$ domain") in the C-terminus of IGF1 that binds the IGF1 receptor [70]. JB-1 administered icv at 0 and $12 \mathrm{~h}$ after ischemia abolished estradiol protection of CA1 neurons (Figure 3B). These findings indicate that ongoing IGF1 receptor signaling is critical for protection by estradiol pretreatment of hippocampal CA1 neurons against ischemia-induced cell death.

In the brain, estradiol [13;71;72;73;74] and IGF1 (for review, see [75]) act via their cognate receptors to engage the mitogen-activated protein kinase (MAPK) and phosphatidylinositol-3-kinase (PI3K) signaling pathways. Work from the laboratory of Luis Garcia-Segura suggests that upon stimulation with estradiol, ER $\alpha$ and IGF1 receptors form a macromolecular signaling complex in the plasma membrane, which recruits and activates downstream kinases including MAPK [12;76;77]. Therefore, we examined the role of MAPK signaling in estradiol neuroprotection in a rat model of global ischemia by icv administration of the ERK/MAPK inhibitor PD98059 at 0 and $12 \mathrm{~h}$ after reperfusion [46]. As shown in Figure 3C, PD98059 reversed the protective effects of estradiol on CA1 neurons. Global ischemia also promotes rapid dephosphorylation and inactivation of the p42/44 MAPK (ERK; Figure 4A,B) and the transcription factor cAMP-response element binding protein (CREB; Figure 4C,D), assessed at 1 and $3 \mathrm{~h}$ after ischemia. Estradiol pretreatment intervenes at the level of ERK/MAPK signaling to prevent ischemia-induced dephosphorylation and inactivation of ERK and CREB, demonstrating that estradiol acts via the classical ERs and IGF1 receptors, which converge on ERK/MAPK and CREB to promote neuronal survival after global ischemia. Ischemia also activates the executioner caspase- 3 and downregulates the antiapoptotic protein Bcl-2, a known gene target of CREB in CA1; estradiol pretreatment also reverses these responses to ischemia [46]. Interestingly, blockade of ERK/MAPK does not prevent ischemia-induced downregulation of Bcl-2, which may be a direct target of ER $\alpha$. Hence, expression of Bcl-2 may be necessary but not sufficient for neuronal survival in the face of global ischemia [46].

\subsection{Estradiol pretreatment also improves functional outcomes after global ischemia}

The data reviewed above clearly show that pretreatment of animals with physiological levels of estradiol ameliorates hippocampal injury associated with global ischemia. Indeed this has 
been verified by many investigators over the past decade, and estradiol pretreatment appears to regulate a large number of downstream effectors of neuronal survival after global ischemia. This includes activation of ERK/MAPK, PI3K, and CREB, upregulation of Bcl-2, BDNF and seladin-1 as well as inhibition of GSK-3 $\beta$ and dickkopf- 1 (an antagonist of the Wnt/ $\beta$-catenin signaling pathway), attenuation of NADPH oxidase activity and reduction of superoxide production $[12 ; 23 ; 76 ; 78 ; 79 ; 80 ; 81 ; 82 ; 83 ; 84]$. Several of these mechanisms, including roles for both ER $\alpha$ and $E R \beta$, also pertain to neuroprotective actions of estradiol in cultured hippocampal neurons exposed to excitotoxic glutamate [85;86]. Although much is known about the impact of estradiol pretreatment on neuronal survival, its impact on functional outcome assessed behaviorally is not as well studied. We investigated whether our estradiol pretreatment paradigm improves ischemia-induced deficits in visual and spatial working memory in young, OVX female rats. Global ischemia significantly impairs visual and spatial memory, assessed by object recognition and object placement tests, when assessed 6-9 days after injury (Figure 5). Estradiol reverses the impairment of visual memory and also prevents ischemia-induced deficits in spatial memory tests with short $(1,7$ min; Figure 5), but not longer (15 min) retention intervals. Thus, estradiol at near physiological levels improves functional recovery after global ischemia [87]. Others have shown improved performance in the Morris water maze, a classical test of hippocampal function, in ischemic rats pretreated with estradiol [88;89]. An exciting report from another investigator showed that a 15-day pretreatment with estradiol prior to ischemia rescued CA1 neurons and provided significant cognitive benefits, which lasted for 6 months after ischemia [90]. These findings have important implications for intervention in the neurological sequelae associated with global ischemia.

The results thus far indicate that estradiol pretreatment ameliorates global ischemia-induced hippocampal damage and cognitive deficits. We are now beginning to assess the functional integrity of hippocampal-based synaptic plasticity after ischemia. To address this issue, we are measuring basal synaptic transmission and synaptic plasticity at CA1 synapses from ischemic rats with or without estradiol pretreatment. As reported by others [91], our preliminary results suggest that global ischemia significantly impairs basal synaptic transmission at Schaffer collateral-CA1 synapses and abolishes long-term potentiation (LTP) by 3 days after injury. Estradiol pretreatment prevents the ischemia-induced deficit in both basal synaptic transmission and LTP (unpublished observations). Thus, both behavioral and electrophysiological findings support the conclusion that long-term pretreatment with estradiol at physiological levels improves the functional integrity of insulted hippocampal CA1 pyramidal neurons.

\section{Pretreatment with estradiol in older animals}

Our findings and results from several independent laboratories cited above clearly show that estrogens protect against global ischemia-induced hippocampal injury and improve functional outcomes when administered to young animals. Rates of heart disease increase substantially in postmenopausal women, placing them at increased risk for a global ischemic event. The risk of cardiovascular disease is also increased in younger women who experience ovarian hormone disruption as a consequence of premature ovarian failure or functional hypothalamic amenorrhea [92;93]. Likewise, the Framingham Heart Study showed that natural menopause before age 42 is associated with a significantly increased risk of ischemic stroke [94]. Future stroke studies with measures of endogenous hormones are needed to inform the underlying mechanisms so that novel prevention strategies for midlife women can be considered. It is not clear that work carried out almost exclusively in young animals will be predictive of outcomes in older animals or humans. The aging brain, including the hippocampus, undergoes a myriad of biochemical, morphological and functional changes that could alter the pattern of vulnerability to cerebral ischemia 
[95;96;97;98;99;100;101;102;103]. Brain cells of older animals exhibit changes including ATP depletion, enhanced intracellular calcium, decreased ability to recover calcium homeostasis, loss of mitochondrial homeostasis and increased propensity to form free radicals [104]. Hippocampal synapses of aged female rats respond differently to estradiol than do synapses in the young hippocampus [105;106], and this age-related difference in morphological response to estradiol correlates with altered subcellular distribution of ER $\alpha$ (reviewed in [107]). However, aged female rhesus monkeys retain the capacity to increase spine density in response to estradiol [108]. In addition to direct actions on hippocampal neurons, estrogens may affect hippocampal neurons indirectly via ERs expressed in basal forebrain cholinergic neurons, which innervate the CA1 [109;110]. The actions of estrogens on these circuits may also change with age, both in rats [111;112] and in rhesus monkeys [113]. These circuits are important for memory, and it is notable that women begin to report memory declines early in the menopausal transition [114;115]. Emerging data on estrogens and memory in middle-aged and older rodents $[116 ; 117 ; 118]$ as well as human and nonhuman primates $[114 ; 119 ; 120 ; 121 ; 122 ; 123 ; 124]$ point to the need for better understanding of the interactions between age per se and loss of ovarian steroids on brain function.

A limited number of studies have examined models of cerebral ischemia in older animals. In one study involving global ischemia in male rats, older (18-22 month) animals exhibited a more pronounced loss of CA1 and striatal neurons than did younger (5-6 month) animals [125]. In addition, there may be region-specific changes in vulnerability to global ischemia; whereas the hippocampal CA1 is more vulnerable in younger animals, the striatum and cortex may be more vulnerable in older rats [126]. There may also be an earlier appearance and more severe progression of lesions in older rats [127]. In animal models of focal ischemia, infarct volumes are greater in older animals [126;128]. However, estradiol pretreatment reduces the volume of brain infarcts produced by focal ischemia (MCAO) in middle-aged female rats that had been OVX for 1 week before experimentation [129;130] and is still effective in older (16 mo) female rats [131]. In contrast, estradiol no longer reduced the volume of infarcts in young females that were OVX for 10 weeks before insult [132]. These findings raise the possibility that treatments such as estradiol, which are effective in young animals, would not necessarily be effective in older animals, especially after prolonged hormone deprivation.

It is imperative to answer these questions, as the ability of postmenopausal hormone therapy to protect against the neuronal death associated with cardiac arrest or stroke remains controversial. As noted above, the results of multicenter trials question the ability of hormone therapy to reduce the occurrence or incidence of cardiovascular disease and stroke in postmenopausal women [33;35]. Data from the WHI Memory Study (WHIMS) also indicate that hormone treatment instituted years after menopause does not protect against dementia or cognitive decline in elderly women [32;34]. One interpretation of the clinical findings is that hormones initiated early in the menopause might provide neuroprotection, whereas hormones initiated years after menopause may have no benefit or even cause harm ("critical period hypothesis") [133;134;135;136;137;138]. Indeed, reports in female rats suggest that the ability of estradiol to prevent the effects of aging and ovarian hormone withdrawal on cognition are abolished if treatment is delayed (e.g. for 5-10 mo) after OVX [116;139]. Therefore, we have sought to ascertain whether there is such a critical period for the neuroprotective actions of estradiol in global ischemia.

\subsection{Estradiol pretreatment retains some neuroprotective actions in older rats}

Whether estradiol retains its neuroprotective actions in middle-aged females, and the relationship between aging and the prolonged absence of normal levels of ovarian hormones in the outcome of global ischemia, were unanswered questions when we began our studies. Also unknown was whether the age-related decline in IGF1, which engages in 
physiologically relevant cross-talk with estrogens in the brain (see section 2.1), contributes to ischemia-induced neurodegeneration and cognitive impairment during and after the perimenopausal transition. We first evaluated the neuroprotective actions of estradiol pretreatment in middle-aged (12-14 mo) female gerbils that were left intact or OVX and treated with placebo or timed-release estradiol pellets for 2 weeks prior to ischemia. All gerbils had substantial CA1 injury that was not significantly reduced by estradiol pretreatment [140], raising the possibility that estradiol may not benefit older females. However, a more recent study showed that a single high dose of estradiol $(4 \mathrm{mg} / \mathrm{kg})$, administered 30 min before ischemia to 4, 9 or 18 month-old female gerbils that were OVX for 2 weeks, produced comparable levels of histological protection at all ages [141]. Thus, the dose or timing of hormone administration may be important in determining whether estradiol retains its neuroprotective actions in older animals subjected to global ischemia.

To distinguish the impact of aging per se from the impact of the precipitous decline in ovarian steroids, as occurs in menopausal humans, we next compared gonadally intact, middle-aged female rats with females OVX in middle age to mimic human menopause. We used females at 9-11 months that have been retired as breeders and hence are known to have been fertile and reproductively active. In separate studies, we confirmed that when these animals are OVX and injected with estradiol and progesterone to achieve blood steroid levels equal to those in young (3-4 month) females, they have luteinizing hormone surges that are significantly delayed and reduced in magnitude [69;142]. This impaired neuroendocrine response closely parallels the situation in perimenopausal women [143].

We assessed both hippocampal CA1 neuron survival and behavioral performance in middleaged female rats that were left intact or OVX for 0,1 or 8 weeks followed by estradiol treatment using implantation of sustained release pellets [144]. One week after implantation of estradiol or placebo pellets, females were tested on a battery of behavioral tests to evaluate hippocampal-dependent cognition (object placement and object recognition) as well as open field behavior, spontaneous alternation, and social preference. A significant proportion of these older females had deficits in object placement and/or object recognition, suggesting an effect of age on both aspects of working memory. Two weeks after the initiation of estradiol or placebo treatment, animals underwent transient global ischemia or sham surgery. One week after ischemia surgery, surviving animals were retested in all of the behavioral paradigms, then perfused for histological analysis of hippocampal neuronal survival. In agreement with observations in young animals, global ischemia produced significant neuronal loss in the CA1 and impaired performance on visual and spatial recognition tasks. Estradiol pretreatment significantly increased CA1 pyramidal neuron survival in animals at all OVX durations (Figure 6). However, in marked contrast to findings in young animals, the increased survival of hippocampal neurons was not associated with improved cognitive performance on either the visual or spatial memory task. Therefore, estradiol does retain some neuroprotective effects in older females, even after prolonged hormone withdrawal, but the effects of estradiol pretreatment are different in middle-aged than in young rats. Similar conclusions were reached in the study that compared OVX female gerbils at different ages, which also showed age-related declines in novel object recognition. However, these authors observed some cognitive benefit of estradiol when administered as a high dose to older females just prior to ischemia [141].

Age-related decreases in IGF1 [145] predict increased cardiovascular mortality and morbidity. Higher levels of IGF1 after ischemic stroke in humans are associated with improved functional outcome [146] and inversely correlate with mortality at 3 and 6 months [147]. There is also evidence that estradiol can increase rather than decrease cortical infarct volume after endothelin-1-induced MCAO in reproductively aged females rats [148] and that this may be due to age-related decreases in IGF1 [149]. Because our work in young 
females showed that ongoing brain IGF1 receptor activity is required for estradiol neuroprotection, we examined whether increasing brain levels of IGF1 would reduce neuronal death and enhance the ability of estradiol to rescue hippocampal neurons [150]. To model the postmenopausal state in women, we again used middle-aged female rats that were OVX for 8 weeks. They were implanted with an osmotic mini-pump delivering IGF1 or saline into the lateral ventricle, and half of the rats also received pellets that delivered physiological levels of estradiol. Two weeks later, rats were subjected to global ischemia or sham operation. As expected, ischemia produced massive CA1 cell death evident at 14 days. Significantly more neurons survived in animals treated with either estradiol or IGF1 alone, and combined treatment produced no additive effect (Figure 7).

\subsection{The critical period hypothesis and global ischemia}

Taken together, our findings in middle-aged female rats subjected to transient global ischemia provide little support for the critical period hypothesis. Estradiol pretreatment reduces CA1 pyramidal cell death to the same extent in middle-aged females that are OVX for 0,1 or 8 weeks before experimentation. Moreover, the extent of cell rescue is similar to that reported by us and others in young females (e.g., see Figures 2,3,6,7). Similarly, high dose estradiol pretreatment was effective in reducing neuronal death and cognitive deficits in 18-month-old gerbils, which are likely to have experienced a prolonged period of ovarian hormone deprivation prior to experimentation [141]. Therefore, the aging female hippocampus appears to retain its responsiveness to the neuroprotective actions of estradiol when provided at high physiological or even pharmacological levels prior to global ischemia. Although estradiol did not improve performance on tests of visual or spatial working memory in rats, this was not related to the duration of hormone withdrawal and hence more likely results from greater vulnerability of older animals to ischemia-induced cognitive impairment. Wappler et al. [141] similarly reported more severe behavioral deficits in older female gerbils subjected to ischemia, and estradiol was able to improve behavioral performance in these older animals.

These results are in contrast to findings in a focal ischemia model, where injury is induced by permanent occlusion of the MCAO with a suture. In this model, estradiol pretreatment reduces the size of cortical infarcts in young female rats that are OVX for 1 week before injury but not in females that are OVX for 10 weeks [132]. The loss of estradiol neuroprotection in the long-term OVX females correlated with an impairment of estradiol modulation of central and peripheral inflammatory mediators. Our observations with both estradiol and IGF1 treatment in older females also differ from findings in the endothelin-1 model of MCAO. In the latter model, estradiol pretreatment actually increased infarct size in middle-aged rats that were estrogen-deprived for approximately 5 weeks, and icv infusion of IGF1 was neuroprotective in these animals only if estradiol was also provided [149]. Thus, the critical period hypothesis may pertain to stroke-induced neuronal injury, but not to transient global ischemia. Indeed early reports in the permanent MCAO model showed that estradiol pretreatment was neuroprotective in middle-aged and older female rats that were OVX for a brief period week insult [129;131]. Hence it is unlikely that age is the critical factor. The different findings in focal and global ischemia may reflect fundamental differences in the cellular and molecular mechanisms underlying neuronal death, in the molecular step(s) at which estradiol intervenes to inhibit apoptosis after different types of injury, and/or the brain regions involved. In focal ischemia, the cortex and striatum are the primary sites of injury whereas hippocampal CA1 pyramidal neurons are most vulnerable when the duration of global ischemia is brief. Other important considerations may be the route and/or dose of hormone administration (for review see [151]). For example, our studies employ a high physiological concentration of estradiol $(30-60 \mathrm{pg} / \mathrm{ml})$, a level that would be achieved in intact females only during proestrus. There is a recent report that a 1- 
week pretreatment with very low levels of estradiol (approximately $10 \mathrm{pg} / \mathrm{ml}$, which mimics diestrus) was unable to reduce CA1 pyramidal cell death induced by transient global ischemia in young female rats that were OVX for 10 weeks before experimentation whereas this regimen was highly effective in rats that received estradiol at the time of OVX [82].

\section{Acute treatment with estradiol after reperfusion}

As described above, our experiments lead us to conclude that estradiol pretreatment (i.e., initiated 2 weeks prior to insult) significantly attenuates ischemia-induced neuronal death in hippocampal CA1, and that the benefits of this treatment (at least with respect to neuronal survival) are retained in older individuals even after prolonged ovarian hormone deprivation. Nonetheless, such pretreatment regimens have limited translational potential for three major reasons. First, the results of large clinical trials such as the WHI, HERS and WEST have led to concerns that the risks of long-term ovarian hormone therapy in postmenopausal women may outweigh the benefits. Second, long-term treatment with typical feminizing estrogens (including the endogenous hormone estradiol) will never be applicable to aging men, who comprise a significant fraction of individuals who are at high risk for global ischemia due to cardiac arrest. Third, estradiol pretreatment may be either ineffective [152] or even exacerbate neuropathology after transient global in diabetic animals [153]. Therefore, it is critical to identify therapeutic strategies (1) that can be initiated after an ischemic event, (2) that can be used in both men and women, and (3) that do not pose risks when used in diabetic individuals. Below we summarize our recent work in OVX young and middle-aged females treated acutely with estradiol and other estrogenic compounds at the time of reperfusion.

\subsection{Acute treatment with estradiol in young females}

The demonstration that estradiol administered after an ischemic event is neuroprotective would be of great clinical relevance. We first examined the ability of estradiol administered immediately after global ischemia and reperfusion to protect hippocampal CA1 neurons in young females OVX for 1 week. OVX female rats were subjected to global ischemia or sham surgery and estradiol or vehicle was injected icv at $0 \mathrm{~h}$ after reperfusion. In our initial experiments with $50 \mu \mathrm{g}$ of estradiol, the hormone modestly but significantly reduced ischemia-induced neuronal loss measured 8-9 days after ischemia [87]. These animals also showed improved performance on object recognition (visual memory) tests, but not on object placement (spatial memory) tests (Figure 8). Later studies confirmed these initial observations [154], demonstrating marked increases in neuronal survival at 7 days after ischemia in rats infused icv with $50 \mu \mathrm{g}$ of estradiol (Figure 9). We now know that much lower doses of estradiol ( $2 \mu \mathrm{g}$ ) are also effective in this paradigm (see section 4.3).

\subsection{Cellular and molecular mediators of acute estradiol neuroprotection in young females}

We have carried out several experiments to characterize the receptor(s) and downstream signaling pathways that mediate estradiol neuroprotection when given acutely after global ischemia. As expected, the classical ER antagonist ICI 182,780 given icv concurrently with estradiol can block the neuroprotective actions of acute estradiol (data not shown). However, other observations suggest that the cellular and molecular mediators of estradiol protection when administered after ischemia differ from those involved when estradiol is provided as a long-term pretreatment. As shown in Figure 10, an ER $\alpha$ - but not an ER $\beta$-selective agonist mimics the actions of estradiol, and blockade of IGF1 receptors with JB-1 does not reverse this form of protection. We next examined a role for PI3K/protein kinase B (Akt) signaling in this form of estradiol protection. We administered estradiol $(50 \mu \mathrm{g})$ in the presence or absence of the PI3K inhibitor LY294002 at $0 \mathrm{~h}$ and $12 \mathrm{~h}$ after surgery [154]. LY294002 did not detectably alter the number or appearance of surviving neurons in sham animals or in 
ischemic animals injected with vehicle, but abrogated the neuroprotective effects of estradiol in CA1 (Figure 9). Global ischemia promoted early dephosphorylation and activation of GSK-3 $\beta$ and the forkhead transcription factor FOXO3A, which are known Akt targets whose inhibition promotes cell survival. Estradiol administered at the onset of reperfusion also prevented ischemia-induced dephosphorylation and activation of GSK3 $\beta$ and FOXO3A, and also prevented activation of caspase-3 [154]. These findings are in agreement with a number of reports on estradiol neuroprotection both in vivo and in vitro. In addition, as shown in Figure 11, acutely administered estradiol also maintained p-CREB in the early postischemic period, similar to our findings with estradiol pretreatment. These findings support a model whereby estradiol administered at the time of reperfusion works by activation of PI3K/Akt signaling to maintain CREB activation, thereby promoting neuronal survival in the face of global ischemia. They also suggest that ongoing activation of CREB signaling may be a common downstream effector of estradiol protection when the hormone is administered either before or after injury.

It is now clear that estrogens initiate rapid signaling events in neurons by binding to recognition molecules other than the classical receptors ER $\alpha$ and ER $\beta$. Estrogens alter the excitability of neurons with latencies of a few seconds and stimulate Akt, MAPK and cAMP production within minutes $[24 ; 25 ; 74 ; 155 ; 156 ; 157 ; 158 ; 159 ; 160 ; 161 ; 162 ; 163 ; 164 ; 165]$. Many such rapid responses occur in cells lacking ER $\alpha$ and ER $\beta$, and/or under conditions of ER $\alpha$ and ER $\beta$ blockade (see $[166 ; 167 ; 168]$ ). Recent studies reveal the existence of transmembrane receptors capable of responding to steroids with cellular activation. One such receptor, GPR30, is a member of the G protein-coupled receptor superfamily and mediates transcription-dependent and independent actions of estrogens $[169 ; 170 ; 171 ; 172 ; 173 ; 174 ; 175]$. Estradiol exhibits an affinity for GPR30 similar to that for ER $\alpha$ and ER $\beta$, consistent with a role for GPR30 in the pleiotropic actions of estrogens on neurons [176;177;178]. In cell lines, estradiol binding to GPR30 stimulates production of cAMP, mobilization of calcium and activation of growth factor signaling $[172 ; 173 ; 179 ; 180]$. G1 is an agent that was identified by a combination of virtual and biomolecular screening [176] as an agonist that binds selectively to GPR30, but not to intracellular ER $\alpha$ and ER $\beta$, which are thought to mediate the undesirable effects of longterm hormone treatment in menopausal women.

Therefore, we evaluated the ability of estradiol and of the GPR30 agonist G1 to reduce ischemia-induced CA1 pyramidal cell death when administered into the lateral ventricle after ischemia [181]. We examined young female rats that were OVX for 1 week prior to insult and administered vehicle, estradiol $(2.2 \mu \mathrm{g})$ or the selective GPR30 agonist G1 (50 $\mu \mathrm{g})$ as a single infusion at the onset of reperfusion. Animals were killed 7 days later, and surviving CA1 pyramidal neurons were quantified as described above. As shown in Figure 12 , animals subjected to ischemia and infused with vehicle suffered approximately $90 \%$ loss of CA1 neurons when compared to sham-operated females. In contrast, $60-65 \%$ of CA1 neurons survived in females treated with a single infusion of either estradiol or G1 after ischemia. This degree of neuron survival is equivalent to or even slightly better than that observed in our work with long-term ( 2 week) estradiol pretreatment [46;47;144].

Certain electrophysiological effects of estradiol on hippocampal slices occur with a short latency and are retained in slices derived from mice with genetic deletions of the classical estrogen receptors. Therefore, we also compared the ability of estradiol and G1 to modify CA1 neuron responses to excitatory inputs from the Schaffer collaterals recorded from hippocampal slices in vitro. Slices were derived from young female rats that were OVX for at least 1 week prior to experimentation. Application of either $100 \mathrm{nM}$ estradiol or G1 to hippocampal slices significantly increases the EPSC amplitude in $~ 60 \%$ of CA1 pyramidal neurons in response to stimulation of the Schaffer collaterals [5]. The fraction of cells that 
responded is comparable to that reported for estradiol by other laboratories [156;182;183]. Pre-application of either estradiol or G1 occluded any further response to the other agent, suggesting that they are acting at the same cellular target. Estradiol and G1 at $10 \mathrm{nM}$ also have identical effects on field EPSPs recorded in the CA1 pyramidal cell layer [181]. These findings suggest that GPR30 or some as yet unidentified target of G1 may mediate the neuroprotective actions of estradiol when given acutely after ischemia.

\subsection{Similarities and differences between long-term and acute estradiol protection}

Our work in young, OVX female rats demonstrates that estradiol administered as a single injection immediately after global ischemia is as effective as long-term hormone pretreatment in promoting survival of CA1 pyramidal neurons. The acute estradiol treatment also attenuates ischemia-induced cognitive dysfunction, albeit perhaps not as effectively as the long-term pretreatment regimen. Moreover, our data are consistent with the interpretations: (1) that extranuclear estrogen receptors may mediate the neuroprotective actions of estradiol when administered in proximity to an ischemic event and (2) that persistent activation of CREB signaling in the early hours after ischemia may be a common downstream effector of estradiol protection when the hormone is administered either as a long-term pretreatment or acutely after insult. These conclusions are similar to those reached by an independent laboratory that administered two membrane-impermeable estradiol conjugates to young, OVX females rats 60 min before 10 min 4-VO [89]. Both compounds rescued a significant fraction of CA1 pyramidal neurons and improved behavioral outcomes in treated animals. Similar to our findings, the protective effects of conjugated estradiol were blocked by ICI 182,780 and by a PI3K inhibitor, and neuroprotection was associated with increased p-CREB in the CA1. Raval et al. [184] also reported that the neuroprotective actions of estradiol in global ischemia induced by carotid artery occlusion and systemic hypotension were accompanied by increased hippocampal p-CREB and CREB mRNA. Interestingly, GPR30 is also reported to mediate the protective effects of estradiol during myocardial ischemia-reperfusion, and this action is PI3K-dependent [185]. Moreover, extranuclear ER $\alpha$ was recently implicated in the reendothelialization of the carotid artery in OVX female mice [186]. Thus, extranuclear ER $\alpha$ and GPR30, perhaps in part via PI3K activation, may contribute to cardioprotective as well as neuroprotective actions of estradiol.

Nonetheless, even though histological analysis suggests that long-term and acute estradiol rescue approximately equal number of hippocampal neurons, our findings clearly suggest that the underlying mechanisms may be distinct. Estradiol can act via either ER $\alpha$ or ER $\beta$ when provided as a long-term pretreatment, and co-signaling through brain IGF1 receptors is required (Figure 3). In contrast, an ER $\alpha$ but not an ER $\beta$ agonist is neuroprotective when given after ischemia, and the ability of acute estradiol to improve hippocampal neuron survival is not dependent on IGF1 receptor signaling in the early post-ischemic period (Figure 10). Moreover, the GPR30 agonist G1, like estradiol, significantly reduces CA1 pyramidal cell death when given as a single injection at the onset of reperfusion (Figure 12). One possibility is that either non-nuclear ER $\alpha$ or GPR30 can mediate this form of protection. This conclusion would be similar to those drawn in a recent study on estradiol's protective actions against glutamate excitotoxicity in a hippocampal cell line [187]. These investigators reported that estradiol, the ER $\alpha$-selective agonist PPT and G1 attenuated glutamate-induced neurotoxicity in at least one cell line. An ER $\beta$ agonist was ineffective, and the protective actions of estradiol were reversed by either ICI 182,780 or a selective GPR30 antagonist. Alternatively, it is possible that GPR30 or an as yet unidentified target of estradiol, G1 and ER $\alpha$-selective agonists may mediate the neuroprotective actions of estradiol when given acutely after ischemia. Therefore, the cellular identity of the estradiol recognition site(s) that mediate neuroprotection when the hormone is given after ischemia remains to be determined. 


\subsection{Acute treatment with estradiol in older females}

It is essential to determine whether estrogenic compounds administered after ischemia are neuroprotective in older animals if such treatments are to be translated into the clinical arena. As described above, our work with chronic estradiol pretreatment in middle-aged female rats showed that hormone pretreatment reduced CA1 pyramidal cell death following global ischemia even when females were deprived of ovarian hormones for 8 weeks by surgical OVX. Therefore, we investigated whether acute administration of estradiol and of estrogenic compounds that do not bind to $\mathrm{ER} \alpha$ and $\mathrm{ER} \beta$ are neuroprotective in older animals after prolonged hormonal withdrawal [181]. We tested estradiol and 2 other compounds, G1 and STX, in middle-aged females that were OVX for 8 weeks before ischemia. STX is a diphenylacrylamide compound that does not bind ER $\alpha$ or ER $\beta$ but that mimics short latency estradiol modulation of hypothalamic ion channels through the activation of a G-protein coupled receptor (for review see [167]). Middle-aged female rats that were OVX for 8 weeks underwent $10 \mathrm{~min}$ global ischemia and were then injected icv with a single dose of estradiol $(2.2 \mu \mathrm{g}), \mathrm{G} 1(50 \mu \mathrm{g})$ or STX $(50 \mu \mathrm{g})$ immediately upon reperfusion. As shown in Figure 13, the number of surviving CA1 pyramidal neurons at 7 days was significantly increased in ischemic animals treated with estradiol, G1 or STX. All three compounds promoted survival of approximately $50 \%$ of CA1 pyramidal neurons.

Because it is not feasible to administer estradiol or other compounds directly into the brain after ischemia in humans, we also determined whether estradiol would rescue CA1 neurons when administered systemically (subcutaneous) in middle-aged females that were OVX for 8 weeks before injury [181] (Figure 13). We used a dose $(100 \mu \mathrm{g} / \mathrm{kg}$ ) that was reported by Simpkins and colleagues [188] to reduce infarct size after MCAO in rats when injected subcutaneously $30 \mathrm{~min}$ after the onset of MCAO. The number of surviving CA1 pyramidal cells was significantly increased in ischemic animals injected subcutaneously with estradiol, and did not differ significantly from the neuroprotection provided by icv administration of estradiol, G1 and STX. Our findings in older females indicate 1) that early post-ischemic treatment with estradiol, G1 and STX promotes significant and comparable neuroprotection in a clinically relevant model of global ischemia, 2) that non-classical ERs, perhaps $G$ protein-coupled receptors, mediate the neuroprotective actions of these compounds, and 3) that the aging hippocampus retains it sensitivity to this form of neuroprotection even after long-term hormone deprivation.

\section{Conclusions and unresolved questions}

This review described the strategies we adopted over the past decade to investigate the neuroprotective efficacy of estradiol and other estrogenic agents in animal models of transient global ischemia, summarized our key findings and discussed these in relationship to published work from other investigators. In agreement with a vast literature in rodents and in cultured neurons, we find that estradiol rescues a significant number of CA1 pyramidal neurons that would otherwise die in response to global ischemia, and this is true when hormone is provided as a long-term pretreatment at high physiological doses or as an acute treatment at the time of reperfusion. Moreover, both regimens of hormone administration continue to rescue hippocampal neurons in middle-aged females that are OVX for 8 weeks before study to precipitate the prolonged ovarian hormone withdrawal that characterizes human menopause. This suggests that for neuronal damage induced by global ischemia, there may not be a critical time window in the early post-menopause in which estrogens must be administered to retain benefit. However, this conclusion cannot be extrapolated to other forms of neurodegeneration, cognitive aging or even focal ischemia at this time (for review see [138]). Also notable is that in addition to providing histological neuroprotection, both forms of estradiol treatment induce measurable cognitive benefit in younger animals. However, the extent of functional protection with estradiol pretreatment in older females is 
not clear (e.g., see sections 3.1 and 3.2 as well as data from rats in [144] and from gerbils in [141]) and may require modification of traditional behavioral tasks to accommodate agerelated declines in cognitive performance in a subset of older animals (see e.g., [102]). Because of this concern, we have not yet evaluated the effects of acutely administered estradiol, G1 or STX in older females subjected to prolonged hormone withdrawal.

The beneficial effects of a single injection of estradiol administered immediately after insult on neuronal survival and cognitive function, and the ability of agents such as G1 and STX to reduce hippocampal cell death, suggest that development of non-feminizing estrogens may lead to new therapeutic approaches for treating the neuronal damage associated with global ischemia. It is noteworthy in this regard that recent studies of isolated hearts from old (2324 month) OVX rats showed that the selective ER $\alpha$ agonist PPT reduces ischemic injury in the aged, estrogen-deficient heart when administered $45 \mathrm{~min}$ before ischemia. This study provided evidence that PPT acted via a non-genomic mechanism involving subcellular redistribution of ER $\alpha$ and PKC activation [189]. As cardiac arrest (and hence global ischemia) is much more prevalent in older patients, including postmenopausal women, our finding that estradiol and related estrogens retain their efficacy in middle-aged females tested 8 weeks after OVX is highly relevant. Especially promising for future translational studies is our demonstration that estradiol is as effective in older, hormone-withdrawn females when given systemically (subcutaneous) as when infused icv (Figure 13). Yet to be determined is the effective time window for post-ischemic administration of estradiol or other estrogen analogs. In a model of focal ischemia (permanent MCAO), high doses of estradiol were able to reduce infarct volume in about one-third of rats when given as late as $6 \mathrm{~h}$ after the onset of ischemia [188]. This same group has also provided evidence that several non-feminizing estrogens are neuroprotective in focal ischemia [11,21].

It will also be important to assess whether estradiol is neuroprotective in males, including older males, when administered after global ischemia. We believe that this is an extremely important area for future research, especially in view of recent data in male mice subjected to cardiac arrest and cardiopulmonary resuscitation (CA/CPR). Sustained administration of an ER $\beta$ agonist for 3 days after CA/CPR (10 min) in male mice reduced hippocampal injury, and both estradiol and the ER $\beta$ agonist (but not PPT, the ER $\alpha$-selective agonist) improved neuronal survival in the striatum [61]. The same group reported that estradiol also reduced kidney damage in both male and female mice after CA/CPR; these actions were observed in ER $\alpha$ and ER $\beta$ null mice, suggesting that they are independent of the classical ERs [29].

There are also many unanswered questions about the cellular and molecular pathways downstream of estradiol binding to its initial recognition site, be it a classical ER located within the cell or at the plasma membrane or a transmembrane receptor such as GPR30. Several different kinases, including ERK/MAPK and PI3K/Akt (see sections 2.1, 4.2 and [12]), have been implicated in focal and global ischemia by several laboratories. There is also a report that estradiol's ability to reduce hippocampal damage after MCAO is accompanied by decreased hyperphosphorylation of tau and decreased interaction of tau with another kinase, GSK3 $\beta$, which is downstream of PI3K/Akt [190]. In addition to these kinases, there is evidence that protein kinases $\mathrm{C}$ and $\mathrm{G}$ may contribute to the cardioprotective actions of estradiol in global ischemia (e.g., [191;192]). These pathways may be especially important in maintaining mitochondrial integrity, which may play a critical role in the ability of estrogens to attenuate ischemia-induced neuronal death and to delay the progression of chronic neurodegenerative diseases (see [193;194] for recent reviews).

In addition, we have not yet evaluated the potentially important contributions of glia and neuroinflammation to ischemia-induced neuronal death and its reversal by estrogens. As 
summarized in a recent review [195], glia as well as neurons are direct targets of estrogen action, and accumulating evidence implicates astrocytes and microglia as mediators of the neuroprotective actions of estradiol in ischemic injury. Estradiol modulates inflammatory processes in female rodents subjected to focal ischemia [132;196], and these actions may be especially important in older individuals (e.g., see [4]), who are likely to have elevated basal levels of inflammation due to obesity and other age-related diseases. There is also a report that the GPR30 agonist G1 can decrease the production of pro-inflammatory cytokines and reduce disease severity in an animal model of multiple sclerosis [197]. Thus, it is possible that non-feminizing estrogens will have beneficial anti-inflammatory properties.

Another question ripe for exploration is the contribution of hippocampal neurogenesis and its modulation by estrogens in long-term recovery from global ischemia. The subventricular zone of the hippocampal dentate gyrus generates neuronal precursors in adult rodents, and these newly born neurons can be integrated into hippocampal circuits [198;199]. Ischemia and other insults enhance hippocampal neurogenesis in both rodents and primates (reviewed in $[200 ; 201 ; 202]$ ); this response to ischemia is retained, although reduced, in aged rats [203]. Estrogens have complex, sex-dependent effects on hippocampal neurogenesis [204;205], and estradiol and IGF1 interact in the brain of young adult rats to enhance neurogenesis in the dentate gyrus [206]. Estradiol can restore proliferation in the dentate of mice with type I diabetes, a state characterized by reduced IGF1 as well as insulin [207;208]. The neuroprotective actions of estradiol in focal ischemia have already been linked to enhanced neurogenesis (reviewed in [10;12]). Therefore, it could be very informative to investigate the effects of neuroprotective estrogenic compounds on hippocampal neurogenesis, especially in older animals.

Finally, estradiol may act directly or indirectly to counter ischemia-induced epigenetic alterations. In the past few years, several studies have shown that ischemia promotes epigenetic remodeling and silencing of genes implicated in neuronal survival. Estrogenic compounds may exert their neuroprotective action, at least in part, by epigenetic remodeling and activation of these genes, thereby countering the impact of ischemia. Our recent findings demonstrate that global ischemia activates the RE1 gene silencing transcription factor (REST) [209;210], which acts by epigenetic remodeling to silence an array of genes critical to neuronal function and survival such as the AMPA receptor subunit GluR2 [209], the $\mu-$ opioid receptor [210], and the NMDA receptor subunit NR2B (unpublished observations). Many of the gene targets of REST are activated by CREB. Others are putative targets of STAT3 signaling. Chan and colleagues showed that focal ischemia suppresses STAT3 expression, recruitment of STAT3 to the manganese superoxide dismutase (MnSOD) promoter and MnSOD transcription, resulting in overproduction of superoxide anion $\left(\mathrm{O}_{2}{ }^{-}\right)$, which contributes to ischemia-induced neuronal death [211]. These findings are consistent with a role for STAT3-dependent epigenetic remodeling of its target MnSOD in ischemic injury. It will be of interest to examine whether estradiol can act via ER $\alpha$, CREB or STAT3 to promote epigenetic modifications and counter ischemia-induced epigenetic modifications and silencing of prosurvival genes. Finally, ischemic preconditioning (a short ischemic episode that affords neuroprotection) activates polycomb proteins in mature hippocampal neurons [212]. Polycomb proteins act through epigenetic gene silencing to eradicate potential mediators of neuronal death and promote cellular arrest, enabling mature neurons to survive ischemic stroke [213]. Because protection by ischemic preconditioning and estradiol share many commonalities, it would be of interest to examine the impact of estradiol on polycomb proteins and epigenetic remodeling of polycomb target genes implicated in neuronal death.

\section{Research Highlights}


- Estradiol pretreatment attenuates ischemia-induced death of hippocampal neurons.

- Estradiol given immediately after ischemia is highly neuroprotective.

- Estradiol treatment improves cognitive outcomes after global ischemia.

- Estrogens retain their neuroprotective efficacy in hormone-withdrawn older females.

- The transcription factor CREB may be a downstream mediator of estradiol protection.

\section{Acknowledgments}

Supported by R01 MH41414, R01 NS045693, R01 AG AG027702, American Heart Association Development Award 0335285N, and the F. M. Kirby Program in Neural Repair and Protection. The authors wish to acknowledge Dr. Diane Lebesgue for providing comments on the manuscript.

\section{References}

1. Lo EH, Dalkara T, Moskowitz MA. Mechanisms, challenges and opportunities in stroke. Nat Rev Neurosci. 2003; 4:399-415. [PubMed: 12728267]

2. Moskowitz MA, Lo EH, Iadecola C. The science of stroke: mechanisms in search of treatments. Neuron. 2010; 67:181-198. [PubMed: 20670828]

3. Zukin, RS.; Jover, T.; Yokota, H.; Calderone, A.; Simionescu, M.; Lau, CG. Molecular and cellular mechanisms of ischemia. In: Mohr, JP.; Choi, DW.; Grotta, JC.; Weir, B.; Wolf, PA., editors. Stroke Pathophysiology, Diagnosis and Management. New York: Churchill Livingstone; 2004. p. 29-54.

4. Brown CM, Suzuki S, Jelks KA, Wise PM. Estradiol is a potent protective, restorative, and trophic factor after brain injury. Semin Reprod Med. 2009; 27:240-249. [PubMed: 19401955]

5. Lebesgue D, Chevaleyre V, Zukin RS, Etgen AM. Estradiol rescues neurons from global ischemiainduced cell death: multiple cellular pathways of neuroprotection. Steroids. 2009; 74:555-561. [PubMed: 19428444]

6. Alonso de Lecinana M, Egido JA. Estrogens as neuroprotectants against ischemic stroke. Cerebrovasc Dis. 2006; 21 Suppl 2:48-53. [PubMed: 16651814]

7. Hoffman GE, Merchenthaler I, Zup SL. Neuroprotection by ovarian hormones in animal models of neurological disease. Endocrine. 2006; 29:217-231. [PubMed: 16785598]

8. Merchenthaler I, Dellovade TL, Shughrue PJ. Neuroprotection by estrogen in animal models of global and focal ischemia. Ann N Y Acad Sci. 2003; 1007:89-100. [PubMed: 14993043]

9. Simpkins JW, Singh M. More than a decade of estrogen neuroprotection. Alzheimers Dement. 2008; 4:S131-S136. [PubMed: 18631989]

10. Suzuki S, Brown CM, Wise PM. Neuroprotective effects of estrogens following ischemic stroke. Front Neuroendocrinol. 2009; 30:201-211. [PubMed: 19401209]

11. Simpkins JW, Yang SH, Liu R, Perez E, Cai ZY, Covey DF, Green PS. Estrogen-like compounds for ischemic neuroprotection. Stroke. 2004; 35:2648-2651. [PubMed: 15472107]

12. Garcia-Segura, LM.; Arévalo, M-A.; Azcoitia, I.; Luciano, M. New advances. Elsevier: Progress in Brain Research; 2010. Interactions of estradiol and insulin-like growth factor-I signalling in the nervous system; p. 251-272.

13. Raz L, Khan MM, Mahesh VB, Vadlamudi RK, Brann DW. Rapid estrogen signaling in the brain. Neurosignals. 2008; 16:140-153. [PubMed: 18253054]

14. Gibson CL, Gray LJ, Murphy SP, Bath PM. Estrogens and experimental ischemic stroke: a systematic review. J Cereb Blood Flow Metab. 2006; 26:1103-1113. [PubMed: 16437060] 
15. Burguete MC, Torregrosa G, Perez-Asensio FJ, Castello-Ruiz M, Salom JB, Gil JV, Alborch E. Dietary phytoestrogens improve stroke outcome after transient focal cerebral ischemia in rats. Eur J Neurosci. 2006; 23:703-710. [PubMed: 16487152]

16. Lovekamp-Swan T, Glendenning M, Schreihofer DA. A high soy diet reduces programmed cell death and enhances bcl-xL expression in experimental stroke. Neuroscience. 2007; 148:644-652. [PubMed: 17706879]

17. Liang HW, Qiu SF, Shen J, Sun LN, Wang JY, Bruce IC, Xia Q. Genistein attenuates oxidative stress and neuronal damage following transient global cerebral ischemia in rat hippocampus. Neurosci Lett. 2008; 438:116-120. [PubMed: 18467029]

18. Barron AM, Fuller SJ, Verdile G, Martins RN. Reproductive hormones modulate oxidative stress in Alzheimer's disease. Antioxid Redox Signal. 2006; 8:2047-2059. [PubMed: 17034349]

19. Bryant DN, Sheldahl LC, Marriott LK, Shapiro RA, Dorsa DM. Multiple pathways transmit neuroprotective effects of gonadal steroids. Endocrine. 2006; 29:199-207. [PubMed: 16785596]

20. Marin R, Ramirez C, Morales A, Gonzalez M, Alonso R, Diaz M. Modulation of Abeta-induced neurotoxicity by estrogen receptor alpha and other associated proteins in lipid rafts. Steroids. 2008; 73:992-996. [PubMed: 18242653]

21. Simpkins JW, Wen Y, Perez E, Yang S, Wang X. Role of nonfeminizing estrogens in brain protection from cerebral ischemia: an animal model of Alzheimer's disease neuropathology. Ann N Y Acad Sci. 2005; 1052:233-242. [PubMed: 16024766]

22. Amantea D, Russo R, Bagetta G, Corasaniti MT. From clinical evidence to molecular mechanisms underlying neuroprotection afforded by estrogens. Pharmacol Res. 2005; 52:119-132. [PubMed: 15967377]

23. Peri A, Danza G, Benvenuti S, Luciani P, Deledda C, Rosati F, Cellai I, Serio M. New insights on the neuroprotective role of sterols and sex steroids: the seladin-1/DHCR24 paradigm. Front Neuroendocrinol. 2009; 30:119-129. [PubMed: 19351544]

24. Fitzpatrick JL, Mize AL, Wade CB, Harris JA, Shapiro RA, Dorsa DM. Estrogen-mediated neuroprotection against beta-amyloid toxicity requires expression of estrogen receptor alpha or beta and activation of the MAPK pathway. J Neurochem. 2002; 82:674-682. [PubMed: 12153491]

25. Mize AL, Shapiro RA, Dorsa DM. Estrogen receptor-mediated neuroprotection from oxidative stress requires activation of the mitogen-activated protein kinase pathway. Endocrinology. 2003; 144:306-312. [PubMed: 12488359]

26. Stice JP, Lee JS, Pechenino AS, Knowlton AA. Estrogen, aging and the cardiovascular system. Future Cardiol. 2009; 5:93-103. [PubMed: 19371207]

27. Booth EA, Lucchesi BR. Estrogen-mediated protection in myocardial ischemia-reperfusion injury. Cardiovasc Toxicol. 2008; 8:101-113. [PubMed: 18683081]

28. Ding Q, Gros R, Limbird LE, Chorazyczewski J, Feldman RD. Estradiol-mediated ERK phosphorylation and apoptosis in vascular smooth muscle cells requires GPR 30. Am J Physiol Cell Physiol. 2009; 297:C1178-C1187. [PubMed: 19741198]

29. Hutchens MP, Nakano T, Kosaka Y, Dunlap J, Zhang W, Herson PS, Murphy SJ, Anderson S, Hurn PD. Estrogen is renoprotective via a nonreceptor-dependent mechanism after cardiac arrest in vivo. Anesthesiology. 112:395-405. [PubMed: 20068453]

30. Xu Y, Armstrong SJ, Arenas IA, Pehowich DJ, Davidge ST. Cardioprotection by chronic estrogen or superoxide dismutase mimetic treatment in the aged female rat. Am J Physiol Heart Circ Physiol. 2004; 287:H165-H171. [PubMed: 14988070]

31. de Lecinana MA, Egido JA, Fernandez C, Martinez-Vila E, Santos S, Morales A, Martinez E, Pareja A, Alvarez-Sabin J, Casado I. Risk of ischemic stroke and lifetime estrogen exposure. Neurology. 2007; 68:33-38. [PubMed: 17200489]

32. Espeland MA, Rapp SR, Shumaker SA, Brunner R, Manson JE, Sherwin BB, Hsia J, Margolis KL, Hogan PE, Wallace R, Dailey M, Freeman R, Hays J. Conjugated equine estrogens and global cognitive function in postmenopausal women: Women's Health Initiative Memory Study. Jama. 2004; 291:2959-2968. [PubMed: 15213207]

33. Grady D, Herrington D, Bittner V, Blumenthal R, Davidson M, Hlatky M, Hsia J, Hulley S, Herd A, Khan S, Newby LK, Waters D, Vittinghoff E, Wenger N. Cardiovascular disease outcomes 
during 6.8 years of hormone therapy: Heart and Estrogen/progestin Replacement Study follow-up (HERS II). Jama. 2002; 288:49-57. [PubMed: 12090862]

34. Rapp SR, Espeland MA, Shumaker SA, Henderson VW, Brunner RL, Manson JE, Gass MLS, Stefanick ML, Lane DS, Hays J, Johnson KC, Coker LH, Dailey M, Bowen D. Effect of Estrogen Plus Progestin on Global Cognitive Function in Postmenopausal Women: The Women's Health Initiative Memory Study: A Randomized Controlled Trial. JAMA. 2003; 289:2663-2672. [PubMed: 12771113]

35. Rossouw JE, Anderson GL, Prentice RL, LaCroix AZ, Kooperberg C, Stefanick ML, Jackson RD, Beresford SA, Howard BV, Johnson KC, Kotchen JM, Ockene J. Risks and benefits of estrogen plus progestin in healthy postmenopausal women: principal results From the Women's Health Initiative randomized controlled trial. JAMA. 2002; 288:321-333. [PubMed: 12117397]

36. Rossouw JE, Prentice RL, Manson JE, Wu L, Barad D, Barnabei VM, Ko M, LaCroix AZ, Margolis KL, Stefanick ML. Postmenopausal Hormone Therapy and Risk of Cardiovascular Disease by Age and Years Since Menopause. JAMA. 2007; 297:1465-1477. [PubMed: 17405972]

37. Viscoli CM, Brass LM, Kernan WN, Sarrel PM, Suissa S, Horwitz RI. A clinical trial of estrogenreplacement therapy after ischemic stroke. N Engl J Med. 2001; 345:1243-1249. [PubMed: 11680444]

38. Pulsinelli WA, Brierley JB. A new model of bilateral hemispheric ischemia in the unanesthetized rat. Stroke. 1979; 10:267-272. [PubMed: 37614]

39. Petito CK, Feldmann E, Pulsinelli WA, Plum F. Delayed hippocampal damage in humans following cardiorespiratory arrest. Neurology. 1987; 37:1281-1286. [PubMed: 3614648]

40. Pulsinelli WA, Brierley JB, Plum F. Temporal profile of neuronal damage in a model of transient forebrain ischemia. Ann Neurol. 1982; 11:491-498. [PubMed: 7103425]

41. Chen J, Adachi N, Liu K, Arai T. The effects of 17beta-estradiol on ischemia-induced neuronal damage in the gerbil hippocampus. Neuroscience. 1998; 87:817-822. [PubMed: 9759969]

42. Kondo Y, Suzuki K, Sakuma Y. Estrogen alleviates cognitive dysfunction following transient brain ischemia in ovariectomized gerbils. Neurosci Lett. 1997; 238:45-48. [PubMed: 9464651]

43. Sudo S, Wen TC, Desaki J, Matsuda S, Tanaka J, Arai T, Maeda N, Sakanaka M. Beta-estradiol protects hippocampal CA1 neurons against transient forebrain ischemia in gerbil. Neurosci Res. 1997; 29:345-354. [PubMed: 9527626]

44. Wang Q, Santizo R, Baughman VL, Pelligrino DA, Iadecola C. Estrogen provides neuroprotection in transient forebrain ischemia through perfusion-independent mechanisms in rats. Stroke. 1999; 30:630-637. [PubMed: 10066863]

45. Jover T, Tanaka H, Calderone A, Oguro K, Bennett MV, Etgen AM, Zukin RS. Estrogen protects against global ischemia-induced neuronal death and prevents activation of apoptotic signaling cascades in the hippocampal CA1. J Neurosci. 2002; 22:2115-2124. [PubMed: 11896151]

46. Jover-Mengual T, Zukin RS, Etgen AM. MAPK signaling is critical to estradiol protection of CA1 neurons in global ischemia. Endocrinology. 2007; 148:1131-1143. [PubMed: 17138646]

47. Miller NR, Jover T, Cohen HW, Zukin RS, Etgen AM. Estrogen can act via estrogen receptor alpha and beta to protect hippocampal neurons against global ischemia-induced cell death. Endocrinology. 2005; 146:3070-3079. [PubMed: 15817665]

48. Huang P, Chandra V, Rastinejad F. Structural Overview of the Nuclear Receptor Superfamily: Insights into Physiology and Therapeutics. Annual Review of Physiology. 72:247-272.

49. Welboren W-J, Sweep FCGJ, Span PN, Stunnenberg HG. Genomic actions of estrogen receptor \{alpha\}: what are the targets and how are they regulated? Endocr Relat Cancer. 2009; 16:10731089. [PubMed: 19628648]

50. Bjornstrom L, Sjoberg M. Mechanisms of Estrogen Receptor Signaling: Convergence of Genomic and Nongenomic Actions on Target Genes. Mol Endocrinol. 2005; 19:833-842. [PubMed: 15695368]

51. Safe S, Kim K. Non-classical genomic estrogen receptor (ER)/specificity protein and ER/activating protein-1 signaling pathways. J Mol Endocrinol. 2008; 41:263-275. [PubMed: 18772268]

52. Kim S-Y, Weiss J, Tong M, Laronda MM, Lee E-J, Jameson JL. Fox12, a Forkhead Transcription Factor, Modulates Nonclassical Activity of the Estrogen Receptor-\{alpha\}. Endocrinology. 2009; 150:5085-5093. [PubMed: 19797124] 
53. Dietz SC, Carroll JS. Interrogating the genome to understand oestrogen-receptor-mediated transcription. Expert Rev Mol Med. 2008; 10:e10. [PubMed: 18377699]

54. Nilsson S, Makela S, Treuter E, Tujague M, Thomsen J, Andersson G, Enmark E, Pettersson K, Warner M, Gustafsson JA. Mechanisms of estrogen action. Physiol Rev. 2001; 81:1535-1565. [PubMed: 11581496]

55. Madak-Erdogan Z, Kieser KJ, Kim SH, Komm B, Katzenellenbogen JA, Katzenellenbogen BS. Nuclear and Extranuclear Pathway Inputs in the Regulation of Global Gene Expression by Estrogen Receptors. Mol Endocrinol. 2008; 22:2116-2127. [PubMed: 18617595]

56. Wong WPS, Tiano JP, Liu S, Hewitt SC, Le May C, Dalle Sp, Katzenellenbogen JA, Katzenellenbogen BS, Korach KS, Mauvais-Jarvis F. Extranuclear estrogen receptor-Î̀ stimulates NeuroD1 binding to the insulin promoter and favors insulin synthesis. Proceedings of the National Academy of Sciences. 2010; 107:13057-13062.

57. Dubal DB, Zhu H, Yu J, Rau SW, Shughrue PJ, Merchenthaler I, Kindy MS, Wise PM. Estrogen receptor alpha, not beta, is a critical link in estradiol-mediated protection against brain injury. Proc Natl Acad Sci U S A. 2001; 98:1952-1957. [PubMed: 11172057]

58. Farr TD, Carswell HV, Gsell W, Macrae IM. Estrogen receptor beta agonist diarylpropiolnitrile (DPN) does not mediate neuroprotection in a rat model of permanent focal ischemia. Brain Res. 2007; 1185:275-282. [PubMed: 17942083]

59. Elzer JG, Muhammad S, Wintermantel TM, Regnier-Vigouroux A, Ludwig J, Schutz G, Schwaninger M. Neuronal estrogen receptor-alpha mediates neuroprotection by 17 beta-estradiol. J Cereb Blood Flow Metab. 2010; 30:935-942. [PubMed: 20010956]

60. Carswell HV, Macrae IM, Gallagher L, Harrop E, Horsburgh KJ. Neuroprotection by a selective estrogen receptor beta agonist in a mouse model of global ischemia. Am J Physiol Heart Circ Physiol. 2004; 287:H1501-H1504. [PubMed: 15155257]

61. Noppens RR, Kofler J, Grafe MR, Hurn PD, Traystman RJ. Estradiol after cardiac arrest and cardiopulmonary resuscitation is neuroprotective and mediated through estrogen receptor-beta. $\mathrm{J}$ Cereb Blood Flow Metab. 2009; 29:277-286. [PubMed: 18957991]

62. Dubal DB, Rau SW, Shughrue PJ, Zhu H, Yu J, Cashion AB, Suzuki S, Gerhold LM, Bottner MB, Dubal SB, Merchanthaler I, Kindy MS, Wise PM. Differential modulation of estrogen receptors (ERs) in ischemic brain injury: a role for ERalpha in estradiol-mediated protection against delayed cell death. Endocrinology. 2006; 147:3076-3084. [PubMed: 16527848]

63. Guan J, Bennet L, Gluckman PD, Gunn AJ. Insulin-like growth factor-1 and post-ischemic brain injury. Progress in Neurobiology. 2003; 70:443-462. [PubMed: 14568359]

64. Lopez-Lopez C, LeRoith D, Torres-Aleman I. Insulin-like growth factor I is required for vessel remodeling in the adult brain. PNAS. 2004; 101:9833-9838. [PubMed: 15210967]

65. Etgen AM, Acosta-Martinez M. Participation of growth factor signal transduction pathways in estradiol facilitation of female reproductive behavior. Endocrinology. 2003 en.2003-0157.

66. Quesada A, Etgen AM. Functional interactions between estrogen and insulin-like growth factor- I in the regulation of alpha $1 \mathrm{~B}$-adrenoceptors and female reproductive function. J Neurosci. 2002; 22:2401-2408. [PubMed: 11896179]

67. Quesada A, Micevych PE. Estrogen interacts with the IGF-1 system to protect nigrostriatal dopamine and maintain motoric behavior after 6-hydroxdopamine lesions. J Neurosci Res. 2004; 75:107-116. [PubMed: 14689453]

68. Todd BJ, Fraley GS, Peck AC, Schwartz GJ, Etgen AM. Central Insulin-Like Growth Factor 1 Receptors Play Distinct Roles in the Control of Reproduction, Food Intake, and Body Weight in Female Rats. Biol Reprod. 2007; 77:492-503. [PubMed: 17567960]

69. Todd BJ, Merhi ZO, Shu J, Etgen AM, Neal-Perry GS. Hypothalamic Insulin-Like Growth FactorI Receptors Are Necessary for Hormone-Dependent Luteinizing Hormone Surges: Implications for Female Reproductive Aging. Endocrinology. 2010; 151:1356-1366. [PubMed: 20097715]

70. Pietrzkowski Z, Wernicke D, Porcu P, Jameson BA, Baserga R. Inhibition of cellular proliferation by peptide analogues of insulin-like growth factor 1. Cancer Res. 1992; 52:6447-6451. [PubMed: 1423292]

71. Bourque M, Dluzen DE, Di Paolo T. Neuroprotective actions of sex steroids in Parkinson's disease. Frontiers in Neuroendocrinology. 2009; 30:142-157. [PubMed: 19410597] 
72. Eisinger-Mathason TSK, Andrade J, Lannigan DA. RSK in tumorigenesis: Connections to steroid signaling. Steroids. 2010; 75:191-202. [PubMed: 20045011]

73. Feldman RD, Gros R. Rapid vascular effects of steroids - a question of balance? Can J Cardiol. 2010; 26 Suppl A:22A-26A. [PubMed: 20101353]

74. Wade CB, Robinson S, Shapiro RA, Dorsa DM. Estrogen receptor (ER)alpha and ERbeta exhibit unique pharmacologic properties when coupled to activation of the mitogen-activated protein kinase pathway. Endocrinology. 2001; 142:2336-2342. [PubMed: 11356680]

75. Samani AA, Yakar S, LeRoith D, Brodt P. The Role of the IGF System in Cancer Growth and Metastasis: Overview and Recent Insights. Endocr Rev. 2007; 28:20-47. [PubMed: 16931767]

76. Mendez P, Azcoitia I, Garcia-Segura LM. Interdependence of oestrogen and insulin-like growth factor-I in the brain: potential for analysing neuroprotective mechanisms. J Endocrinol. 2005; 185:11-17. [PubMed: 15817823]

77. Mendez P, Wandosell F, Garcia-Segura LM. Cross-talk between estrogen receptors and insulinlike growth factor-I receptor in the brain: Cellular and molecular mechanisms. Frontiers in Neuroendocrinology. 2006; 27:391-403. [PubMed: 17049974]

78. Brann DW, Dhandapani K, Wakade C, Mahesh VB, Khan MM. Neurotrophic and neuroprotective actions of estrogen: basic mechanisms and clinical implications. Steroids. 2007; 72:381-405. [PubMed: 17379265]

79. Cardona-Gomez P, Perez M, Avila J, Garcia-Segura LM, Wandosell F. Estradiol inhibits GSK3 and regulates interaction of estrogen receptors, GSK3, and beta-catenin in the hippocampus. Molecular and Cellular Neuroscience. 2004; 25:363-373. [PubMed: 15033165]

80. Varea O, Arevalo M-A, Garrido JJ, Garcia-Segura LM, Wandosell F, Mendez P. Interaction of estrogen receptors with insulin-like growth factor-I and Wnt signaling in the nervous system. Steroids. 75:565-569. [PubMed: 19778547]

81. Wakade C, Khan MM, De Sevilla LM, Zhang QG, Mahesh VB, Brann DW. Tamoxifen neuroprotection in cerebral ischemia involves attenuation of kinase activation and superoxide production and potentiation of mitochondrial superoxide dismutase. Endocrinology. 2008; 149:367-379. [PubMed: 17901229]

82. Zhang QG, Raz L, Wang R, Han D, De Sevilla L, Yang F, Vadlamudi RK, Brann DW. Estrogen attenuates ischemic oxidative damage via an estrogen receptor alpha-mediated inhibition of NADPH oxidase activation. J Neurosci. 2009; 29:13823-13836. [PubMed: 19889994]

83. Zhang QG, Wang R, Khan M, Mahesh V, Brann DW. Role of Dickkopf-1, an antagonist of the Wnt/beta-catenin signaling pathway, in estrogen-induced neuroprotection and attenuation of tau phosphorylation. J Neurosci. 2008; 28:8430-8441. [PubMed: 18716201]

84. Zhang W, Iliff JJ, Campbell CJ, Wang RK, Hurn PD, Alkayed NJ. Role of soluble epoxide hydrolase in the sex-specific vascular response to cerebral ischemia. J Cereb Blood Flow Metab. 2009; 29:1475-1481. [PubMed: 19471280]

85. Zhao L, Brinton RD. Estrogen receptor alpha and beta differentially regulate intracellular $\mathrm{Ca}(2+)$ dynamics leading to ERK phosphorylation and estrogen neuroprotection in hippocampal neurons. Brain Res. 2007; 1172:48-59. [PubMed: 17803971]

86. Zhao L, Wu TW, Brinton RD. Estrogen receptor subtypes alpha and beta contribute to neuroprotection and increased Bcl-2 expression in primary hippocampal neurons. Brain Res. 2004; 1010:22-34. [PubMed: 15126114]

87. Gulinello M, Lebesgue D, Jover-Mengual T, Zukin RS, Etgen AM. Acute and chronic estradiol treatments reduce memory deficits induced by transient global ischemia in female rats. Horm Behav. 2006; 49:246-260. [PubMed: 16125703]

88. Sandstrom NJ, Rowan MH. Acute pretreatment with estradiol protects against CA1 cell loss and spatial learning impairments resulting from transient global ischemia. Horm Behav. 2007; 51:335345. [PubMed: 17239878]

89. Yang LC, Zhang QG, Zhou CF, Yang F, Zhang YD, Wang RM, Brann DW. Extranuclear estrogen receptors mediate the neuroprotective effects of estrogen in the rat hippocampus. PLoS One. 2010; 5:e9851. [PubMed: 20479872] 
90. Plamondon H, Morin A, Charron C. Chronic 17beta-estradiol pretreatment and ischemia-induced hippocampal degeneration and memory impairments: a 6-month survival study. Horm Behav. 2006; 50:361-369. [PubMed: 16815389]

91. Dai X, Chen L, Sokabe M. Neurosteroid estradiol rescues ischemia-induced deficit in the longterm potentiation of rat hippocampal CA1 neurons. Neuropharmacology. 2007; 52:1124-1138. [PubMed: 17258238]

92. Bairey Merz CN, Johnson BD, Sharaf BL, Bittner V, Berga SL, Braunstein GD, Hodgson TK, Matthews KA, Pepine CJ, Reis SE, Reichek N, Rogers WJ, Pohost GM, Kelsey SF, Sopko G. Hypoestrogenemia of hypothalamic origin and coronary artery disease in premenopausal women: a report from the NHLBI-sponsored WISE study. J Am Coll Cardiol. 2003; 41:413-419. [PubMed: 12575968]

93. Sutton-Tyrrell K, Wildman RP, Matthews KA, Chae C, Lasley BL, Brockwell S, Pasternak RC, Lloyd-Jones D, Sowers MF, Torrens JI. Sex-hormone-binding globulin and the free androgen index are related to cardiovascular risk factors in multiethnic premenopausal and perimenopausal women enrolled in the Study of Women Across the Nation (SWAN). Circulation. 2005; 111:1242-1249. [PubMed: 15769764]

94. Lisabeth LD, Beiser AS, Brown DL, Murabito JM, Kelly-Hayes M, Wolf PA. Age at Natural Menopause and Risk of Ischemic Stroke: The Framingham Heart Study. Stroke. 2009; 40:10441049. [PubMed: 19233935]

95. Barnes CA, Rao G, Houston FP. LTP induction threshold change in old rats at the perforant path-granule cell synapse. Neurobiol Aging. 2000; 21:613-620. [PubMed: 11016529]

96. Barnes CA, Rao G, Orr G. Age-related decrease in the Schaffer collateral-evoked EPSP in awake, freely behaving rats. Neural Plast. 2000; 7:167-178. [PubMed: 11147459]

97. Burke SN, Barnes CA. Senescent synapses and hippocampal circuit dynamics. Trends in Neurosciences. 2010; 33:153-161. [PubMed: 20071039]

98. Funahashi T, Floyd RA, Carney JM. Age effect on brain $\mathrm{pH}$ during ischemia/reperfusion and $\mathrm{pH}$ influence on peroxidation. Neurobiol Aging. 1994; 15:161-167. [PubMed: 7838286]

99. Kadar T, Silbermann M, Steinhagen-Thiessen E, Levy A. Age-related changes in the cholinergic components within the central nervous system of CW1 female mice. I. Structural analysis. Mech Ageing Dev. 1989; 47:133-144. [PubMed: 2716365]

100. Kadar T, Silbermann M, Weissman BA, Levy A. Age-related changes in the cholinergic components within the central nervous system. II. Working memory impairment and its relation to hippocampal muscarinic receptors. Mech Ageing Dev. 1990; 55:139-149. [PubMed: 2232908]

101. McEwen BS. Sex, stress and the hippocampus: allostasis, allostatic load and the aging process. Neurobiol Aging. 2002; 23:921-939. [PubMed: 12392796]

102. Freeman WM, Vanguilder HD, Bennett C, Sonntag WE. Cognitive performance and age-related changes in the hippocampal proteome. Neuroscience. 2009; 159:183-195. [PubMed: 19135133]

103. VanGuilder HD, Yan H, Farley JA, Sonntag WE, Freeman WM. Aging alters the expression of neurotransmission-regulating proteins in the hippocampal synaptoproteome. J Neurochem. 113:1577-1588. [PubMed: 20374424]

104. Dröge W, Schipper HM. Oxidative stress and aberrant signaling in aging and cognitive decline. Aging Cell. 2007; 6:361-370. [PubMed: 17517043]

105. Adams MM, Fink SE, Janssen WG, Shah RA, Morrison JH. Estrogen modulates synaptic Nmethyl-D-aspartate receptor subunit distribution in the aged hippocampus. J Comp Neurol. 2004; 474:419-426. [PubMed: 15174084]

106. Yildirim M, Janssen WG, Tabori NE, Adams MM, Yuen GS, Akama KT, McEwen BS, Milner TA, Morrison JH. Estrogen and aging affect synaptic distribution of phosphorylated LIM kinase (pLIMK) in CA1 region of female rat hippocampus. Neuroscience. 2008; 152:360-370. [PubMed: 18294775]

107. Adams MM, Morrison JH. Estrogen and the aging hippocampal synapse. Cereb Cortex. 2003; 13:1271-1275. [PubMed: 14615293]

108. Hao J, Janssen WG, Tang Y, Roberts JA, McKay H, Lasley B, Allen PB, Greengard P, Rapp PR, Kordower JH, Hof PR, Morrison JH. Estrogen increases the number of spinophilin- 
immunoreactive spines in the hippocampus of young and aged female rhesus monkeys. J Comp Neurol. 2003; 465:540-550. [PubMed: 12975814]

109. Toran-Allerand CD, Miranda RC, Bentham WD, Sohrabji F, Brown TJ, Hochberg RB, MacLusky NJ. Estrogen receptors colocalize with low-affinity nerve growth factor receptors in cholinergic neurons of the basal forebrain. Proc Natl Acad Sci U S A. 1992; 89:4668-4672. [PubMed: 1316615]

110. Towart LA, Alves SE, Znamensky V, Hayashi S, McEwen BS, Milner TA. Subcellular relationships between cholinergic terminals and estrogen receptor-alpha in the dorsal hippocampus. J Comp Neurol. 2003; 463:390-401. [PubMed: 12836175]

111. Gibbs RB. Effects of ageing and long-term hormone replacement on cholinergic neurones in the medial septum and nucleus basalis magnocellularis of ovariectomized rats. J Neuroendocrinol. 2003; 15:477-485. [PubMed: 12694373]

112. Gibbs RB, Mauk R, Nelson D, Johnson DA. Donepezil treatment restores the ability of estradiol to enhance cognitive performance in aged rats: evidence for the cholinergic basis of the critical period hypothesis. Horm Behav. 2009; 56:73-83. [PubMed: 19303882]

113. Kompoliti K, Chu Y, Polish A, Roberts J, McKay H, Mufson EJ, Leurgans S, Morrison JH, Kordower JH. Effects of estrogen replacement therapy on cholinergic basal forebrain neurons and cortical cholinergic innervation in young and aged ovariectomized rhesus monkeys. J Comp Neurol. 2004; 472:193-207. [PubMed: 15048687]

114. Meyer PM, Powell LH, Wilson RS, Everson-Rose SA, Kravitz HM, Luborsky JL, Madden T, Pandey D, Evans DA. A population-based longitudinal study of cognitive functioning in the menopausal transition. Neurology. 2003; 61:801-806. [PubMed: 14504324]

115. Woods NF, Smith-Dijulio K, Percival DB, Tao EY, Taylor HJ, Mitchell ES. Symptoms during the menopausal transition and early postmenopause and their relation to endocrine levels over time: observations from the Seattle Midlife Women's Health Study. J Womens Health (Larchmt). 2007; 16:667-677. [PubMed: 17627402]

116. Daniel JM, Hulst JL, Berbling JL. Estradiol replacement enhances working memory in middleaged rats when initiated immediately after ovariectomy but not after a long-term period of ovarian hormone deprivation. Endocrinology. 2006; 147:607-614. [PubMed: 16239296]

117. Fernandez SM, Frick KM. Chronic oral estrogen affects memory and neurochemistry in middleaged female mice. Behav Neurosci. 2004; 118:1340-1351. [PubMed: 15598143]

118. Frick KM. Estrogens and age-related memory decline in rodents: what have we learned and where do we go from here? Horm Behav. 2009; 55:2-23. [PubMed: 18835561]

119. Fuh JL, Wang SJ, Lee SJ, Lu SR, Juang KD. A longitudinal study of cognition change during early menopausal transition in a rural community. Maturitas. 2006; 53:447-453. [PubMed: 16198073]

120. Fuh JL, Wang SJ, Lu SR, Juang KD, Lee SJ. Alterations in cognitive function during the menopausal transition. J Am Geriatr Soc. 2003; 51:431-432. [PubMed: 12588594]

121. Lacreuse A. Effects of ovarian hormones on cognitive function in nonhuman primates. Neuroscience. 2006; 138:859-867. [PubMed: 16310311]

122. Lacreuse A, Wilson ME, Herndon JG. Estradiol, but not raloxifene, improves aspects of spatial working memory in aged ovariectomized rhesus monkeys. Neurobiol Aging. 2002; 23:589-600. [PubMed: 12009508]

123. Sherwin BB. Estrogen and cognitive aging in women. Neuroscience. 2006; 138:1021-1026. [PubMed: 16310965]

124. Sherwin BB, Henry JF. Brain aging modulates the neuroprotective effects of estrogen on selective aspects of cognition in women: a critical review. Front Neuroendocrinol. 2008; 29:88-113. [PubMed: 17980408]

125. Yao H, Sadoshima S, Ooboshi H, Sato Y, Uchimura H, Fujishima M. Age-related vulnerability to cerebral ischemia in spontaneously hypertensive rats. Stroke. 1991; 22:1414-1418. [PubMed: 1750050]

126. Sutherland GR, Dix GA, Auer RN. Effect of age in rodent models of focal and forebrain ischemia. Stroke. 1996; 27:1663-1667. discussion 1668. [PubMed: 8784145] 
127. Canese R, Fortuna S, Lorenzini P, Podo F, Michalek H. Transient global brain ischemia in young and aged rats: differences in severity and progression, but not localisation, of lesions evaluated by magnetic resonance imaging. Magma. 1998; 7:28-34. [PubMed: 9877457]

128. Davis M, Mendelow AD, Perry RH, Chambers IR, James OF. Experimental stroke and neuroprotection in the aging rat brain. Stroke. 1995; 26:1072-1078. [PubMed: 7762026]

129. Wise PM, Dubal DB. Estradiol protects against ischemic brain injury in middle-aged rats. Biol Reprod. 2000; 63:982-985. [PubMed: 10993817]

130. Wise PM, Dubal DB, Wilson ME, Rau SW, Bottner M, Rosewell KL. Estradiol is a protective factor in the adult and aging brain: understanding of mechanisms derived from in vivo and in vitro studies. Brain Res Brain Res Rev. 2001; 37:313-319. [PubMed: 11744096]

131. Alkayed NJ, Murphy SJ, Traystman RJ, Hurn PD, Miller VM. Neuroprotective effects of female gonadal steroids in reproductively senescent female rats. Stroke. 2000; 31:161-168. [PubMed: 10625733]

132. Suzuki S, Brown CM, Dela C, Cruz D, Yang E, Bridwell DA, Wise PM. Timing of estrogen therapy after ovariectomy dictates the efficacy of its neuroprotective and antiinflammatory actions. Proc Natl Acad Sci U S A. 2007; 104:6013-6018. [PubMed: 17389368]

133. Daniel JM, Bohacek J. The critical period hypothesis of estrogen effects on cognition: Insights from basic research. Biochim Biophys Acta. 2010

134. Dumas J, Hancur-Bucci C, Naylor M, Sites C, Newhouse P. Estradiol interacts with the cholinergic system to affect verbal memory in postmenopausal women: evidence for the critical period hypothesis. Horm Behav. 2008; 53:159-169. [PubMed: 17964576]

135. Maki PM. Hormone therapy and cognitive function: is there a critical period for benefit? Neuroscience. 2006; 138:1027-1030. [PubMed: 16488547]

136. Sherwin BB. Estrogen and memory in women: how can we reconcile the findings? Horm Behav. 2005; 47:371-375. [PubMed: 15708768]

137. Sherwin BB. The critical period hypothesis: can it explain discrepancies in the oestrogencognition literature? J Neuroendocrinol. 2007; 19:77-81. [PubMed: 17214869]

138. Sherwin BB. Estrogen therapy: is time of initiation critical for neuroprotection? Nat Rev Endocrinol. 2009; 5:620-627. [PubMed: 19844249]

139. Gibbs RB. Long-term treatment with estrogen and progesterone enhances acquisition of a spatial memory task by ovariectomized aged rats. Neurobiol Aging. 2000; 21:107-116. [PubMed: 10794855]

140. De Butte-Smith M, Nguyen AP, Zukin RS, Etgen AM, Colbourne F. Failure of estradiol to ameliorate global ischemia-induced CA1 sector injury in middle-aged female gerbils. Brain Res. 2007; 1153:214-220. [PubMed: 17462607]

141. Wappler EA, Felszeghy K, Szilagyi G, Gal A, Skopal J, Mehra RD, Nyakas C, Nagy Z. Neuroprotective effects of estrogen treatment on ischemia-induced behavioural deficits in ovariectomized gerbils at different ages. Behav Brain Res. 2010; 209:42-48. [PubMed: 20085782]

142. Neal-Perry GS, Zeevalk GD, Santoro NF, Etgen AM. Attenuation of preoptic area glutamate release correlates with reduced luteinizing hormone secretion in middle-aged female rats. Endocrinology. 2005; 146:4331-4339. [PubMed: 15994345]

143. Weiss G, Skurnick JH, Goldsmith LT, Santoro NF, Park SJ. Menopause and hypothalamicpituitary sensitivity to estrogen. Jama. 2004; 292:2991-2996. [PubMed: 15613667]

144. De Butte-Smith M, Gulinello M, Zukin RS, Etgen AM. Chronic estradiol treatment increases CA1 cell survival but does not improve visual or spatial recognition memory after global ischemia in middle-aged female rats. Horm Behav. 2009; 55:442-453. [PubMed: 19124025]

145. Juul A, Scheike T, Davidsen M, Gyllenborg J, Jorgensen T. Low serum insulin-like growth factor I is associated with increased risk of ischemic heart disease: a population-based case-control study. Circulation. 2002; 106:939-944. [PubMed: 12186797]

146. Bondanelli M, Ambrosio MR, Onofri A, Bergonzoni A, Lavezzi S, Zatelli MC, Valle D, Basaglia $\mathrm{N}$, degli Uberti EC. Predictive value of circulating insulin-like growth factor I levels in ischemic stroke outcome. J Clin Endocrinol Metab. 2006; 91:3928-3934. [PubMed: 16882751] 
147. Denti L, Annoni V, Cattadori E, Salvagnini MA, Visioli S, Merli MF, Corradi F, Ceresini G, Valenti G, Hoffman AR, Ceda GP. Insulin-like growth factor 1 as a predictor of ischemic stroke outcome in the elderly. Am J Med. 2004; 117:312-317. [PubMed: 15336580]

148. Selvamani A, Sohrabji F. Reproductive age modulates the impact of focal ischemia on the forebrain as well as the effects of estrogen treatment in female rats. Neurobiol Aging. 2010; 31:1618-1628. [PubMed: 18829137]

149. Selvamani A, Sohrabji F. The neurotoxic effects of estrogen on ischemic stroke in older female rats is associated with age-dependent loss of insulin-like growth factor-1. J Neurosci. 2010; 30:6852-6861. [PubMed: 20484627]

150. Traub ML, De Butte-Smith M, Zukin RS, Etgen AM. Oestradiol and insulin-like growth factor-1 reduce cell loss after global ischaemia in middle-aged female rats. J Neuroendocrinol. 2009; 21:1038-1044. [PubMed: 19840235]

151. Strom JO, Theodorsson A, Theodorsson E. Dose-related neuroprotective versus neurodamaging effects of estrogens in rat cerebral ischemia: a systematic analysis. J Cereb Blood Flow Metab. 2009; 29:1359-1372. [PubMed: 19458604]

152. Zhang L, Nair A, Krady K, Corpe C, Bonneau RH, Simpson IA, Vannucci SJ. Estrogen stimulates microglia and brain recovery from hypoxia-ischemia in normoglycemic but not diabetic female mice. J Clin Invest. 2004; 113:85-95. [PubMed: 14702112]

153. Shen B, Vetri F, Mao L, Xu HL, Paisansathan C, Pelligrino DA. Aldose reductase inhibition ameliorates the detrimental effect of estrogen replacement therapy on neuropathology in diabetic rats subjected to transient forebrain ischemia. Brain Res. 2010; 1342:118-126. [PubMed: 20417192]

154. Jover-Mengual T, Miyawaki T, Latuszek A, Alborch E, Zukin RS, Etgen AM. Acute estradiol protects CA1 neurons from ischemia-induced apoptotic cell death via the PI3K/Akt pathway. Brain Res. 2010; 1321:1-12. [PubMed: 20114038]

155. Gu G, Rojo AA, Zee MC, Yu J, Simerly RB. Hormonal regulation of CREB phosphorylation in the anteroventral periventricular nucleus. J Neurosci. 1996; 16:3035-3044. [PubMed: 8622133]

156. Gu Q, Korach KS, Moss RL. Rapid action of 17beta-estradiol on kainate-induced currents in hippocampal neurons lacking intracellular estrogen receptors. Endocrinology. 1999; 140:660666. [PubMed: 9927291]

157. Gu Q, Moss RL. 17 beta-Estradiol potentiates kainate-induced currents via activation of the cAMP cascade. J Neurosci. 1996; 16:3620-3629. [PubMed: 8642406]

158. Kelly MJ, Lagrange AH, Wagner EJ, Ronnekleiv OK. Rapid effects of estrogen to modulate G protein-coupled receptors via activation of protein kinase $\mathrm{A}$ and protein kinase $\mathrm{C}$ pathways. Steroids. 1999; 64:64-75. [PubMed: 10323674]

159. Kelly MJ, Levin ER. Rapid actions of plasma membrane estrogen receptors. Trends Endocrinol Metab. 2001; 12:152-156. [PubMed: 11295570]

160. Kelly MJ, Ronnekleiv OK. Control of CNS neuronal excitability by estrogens via membraneinitiated signaling. Mol Cell Endocrinol. 2009; 308:17-25. [PubMed: 19549588]

161. Kelly MJ, Ronnekleiv OK, Ibrahim N, Lagrange AH, Wagner EJ. Estrogen modulation of K(+) channel activity in hypothalamic neurons involved in the control of the reproductive axis. Steroids. 2002; 67:447-456. [PubMed: 11960620]

162. Lagrange AH, Wagner EJ, Ronnekleiv OK, Kelly MJ. Estrogen rapidly attenuates a GABAB response in hypothalamic neurons. Neuroendocrinology. 1996; 64:114-123. [PubMed: 8857605]

163. Qiu J, Bosch MA, Tobias SC, Grandy DK, Scanlan TS, Ronnekleiv OK, Kelly MJ. Rapid Signaling of Estrogen in Hypothalamic Neurons Involves a Novel G-Protein-Coupled Estrogen Receptor that Activates Protein Kinase C. J. Neurosci. 2003; 23:9529-9540. [PubMed: 14573532]

164. Ronnekleiv OK, Malyala A, Kelly MJ. Membrane-initiated signaling of estrogen in the brain. Semin Reprod Med. 2007; 25:165-177. [PubMed: 17447206]

165. Kelly MJ, Qiu J, Wagner EJ, Ronnekleiv OK. Rapid effects of estrogen on G protein-coupled receptor activation of potassium channels in the central nervous system (CNS). J Steroid Biochem Mol Biol. 2002; 83:187-193. [PubMed: 12650715] 
166. Kelly MJ, Ronnekleiv OK. Membrane-initiated estrogen signaling in hypothalamic neurons. Mol Cell Endocrinol. 2008; 290:14-23. [PubMed: 18538919]

167. Qiu J, Ronnekleiv OK, Kelly MJ. Modulation of hypothalamic neuronal activity through a novel G-protein-coupled estrogen membrane receptor. Steroids. 2008; 73:985-991. [PubMed: 18342349]

168. Ronnekleiv OK, Kelly MJ. Diversity of ovarian steroid signaling in the hypothalamus. Frontiers in Neuroendocrinology. 2005; 26:65-84. [PubMed: 16009409]

169. Filardo E, Quinn J, Pang Y, Graeber C, Shaw S, Dong J, Thomas P. Activation of the novel estrogen receptor $\mathrm{G}$ protein-coupled receptor 30 (GPR30) at the plasma membrane. Endocrinology. 2007; 148:3236-3245. [PubMed: 17379646]

170. Filardo EJ, Quinn JA, Frackelton AR Jr, Bland KI. Estrogen action via the G protein-coupled receptor, GPR30: stimulation of adenylyl cyclase and cAMP-mediated attenuation of the epidermal growth factor receptor-to-MAPK signaling axis. Mol Endocrinol. 2002; 16:70-84. [PubMed: 11773440]

171. Filardo EJ, Quinn JA, Sabo E. Association of the membrane estrogen receptor, GPR30, with breast tumor metastasis and transactivation of the epidermal growth factor receptor. Steroids. 2008; 73:870-873. [PubMed: 18289622]

172. Prossnitz ER, Arterburn JB, Sklar LA. GPR30: A G protein-coupled receptor for estrogen. Mol Cell Endocrinol. 2007; 265-266:138-142.

173. Prossnitz ER, Arterburn JB, Smith HO, Oprea TI, Sklar LA, Hathaway HJ. Estrogen signaling through the transmembrane G protein-coupled receptor GPR30. Annu Rev Physiol. 2008; 70:165-190. [PubMed: 18271749]

174. Prossnitz ER, Oprea TI, Sklar LA, Arterburn JB. The ins and outs of GPR30: a transmembrane estrogen receptor. J Steroid Biochem Mol Biol. 2008; 109:350-353. [PubMed: 18406603]

175. Prossnitz ER, Sklar LA, Oprea TI, Arterburn JB. GPR30: a novel therapeutic target in estrogenrelated disease. Trends Pharmacol Sci. 2008; 29:116-123. [PubMed: 18262661]

176. Bologa CG, Revankar CM, Young SM, Edwards BS, Arterburn JB, Kiselyov AS, Parker MA, Tkachenko SE, Savchuck NP, Sklar LA, Oprea TI, Prossnitz ER. Virtual and biomolecular screening converge on a selective agonist for GPR30. Nat Chem Biol. 2006; 2:207-212. [PubMed: 16520733]

177. Thomas P, Dong J. Binding and activation of the seven-transmembrane estrogen receptor GPR30 by environmental estrogens: a potential novel mechanism of endocrine disruption. J Steroid Biochem Mol Biol. 2006; 102:175-179. [PubMed: 17088055]

178. Thomas P, Pang Y, Filardo EJ, Dong J. Identity of an estrogen membrane receptor coupled to a G protein in human breast cancer cells. Endocrinology. 2005; 146:624-632. [PubMed: 15539556]

179. Filardo EJ. Epidermal growth factor receptor (EGFR) transactivation by estrogen via the Gprotein-coupled receptor, GPR30: a novel signaling pathway with potential significance for breast cancer. J Steroid Biochem Mol Biol. 2002; 80:231-238. [PubMed: 11897506]

180. Filardo EJ, Quinn JA, Bland KI, Frackelton AR Jr. Estrogen-induced activation of Erk-1 and Erk-2 requires the G protein-coupled receptor homolog, GPR30, and occurs via trans-activation of the epidermal growth factor receptor through release of HB-EGF. Mol Endocrinol. 2000; 14:1649-1660. [PubMed: 11043579]

181. Lebesgue D, Traub M, De Butte-Smith M, Chen C, Zukin RS, Kelly MJ, Etgen AM. Acute administration of non-classical estrogen receptor agonists attenuates ischemia-induced hippocampal neuron loss in middle-aged female rats. PLoS One. 2010; 5:e8642. [PubMed: 20062809]

182. Wong M, Moss RL. Long-term and short-term electrophysiological effects of estrogen on the synaptic properties of hippocampal CA1 neurons. J Neurosci. 1992; 12:3217-3225. [PubMed: 1353794]

183. Woolley CS, Weiland NG, McEwen BS, Schwartzkroin PA. Estradiol increases the sensitivity of hippocampal CA1 pyramidal cells to NMDA receptor-mediated synaptic input: correlation with dendritic spine density. J Neurosci. 1997; 17:1848-1859. [PubMed: 9030643]

184. Raval AP, Saul I, Dave KR, DeFazio RA, Perez-Pinzon MA, Bramlett H. Pretreatment with a single estradiol-17beta bolus activates cyclic-AMP response element binding protein and protects 
CA1 neurons against global cerebral ischemia. Neuroscience. 2009; 160:307-318. [PubMed: 19272413]

185. Deschamps AM, Murphy E. Activation of a novel estrogen receptor, GPER, is cardioprotective in male and female rats. Am J Physiol Heart Circ Physiol. 2009; 297:H1806-H1813. [PubMed: 19717735]

186. Chambliss KL, Wu Q, Oltmann S, Konaniah ES, Umetani M, Korach KS, Thomas GD, Mineo C, Yuhanna IS, Kim SH, Madak-Erdogan Z, Maggi A, Dineen SP, Roland CL, Hui DY, Brekken RA, Katzenellenbogen JA, Katzenellenbogen BS, Shaul PW. Non-nuclear estrogen receptor alpha signaling promotes cardiovascular protection but not uterine or breast cancer growth in mice. J Clin Invest. 120:2319-2330. [PubMed: 20577047]

187. Gingerich S, Kim GL, Chalmers JA, Koletar MM, Wang X, Wang Y, Belsham DD. Estrogen receptor alpha and G-protein coupled receptor 30 mediate the neuroprotective effects of 17[beta]estradiol in novel murine hippocampal cell models. Neuroscience. 2010 In Press, Corrected Proof.

188. Liu R, Wang X, Liu Q, Yang SH, Simpkins JW. Dose dependence and therapeutic window for the neuroprotective effects of 17beta-estradiol when administered after cerebral ischemia. Neurosci Lett. 2007; 415:237-241. [PubMed: 17331646]

189. Novotny JL, Simpson AM, Tomicek NJ, Lancaster TS, Korzick DH. Rapid estrogen receptoralpha activation improves ischemic tolerance in aged female rats through a novel protein kinase C epsilon-dependent mechanism. Endocrinology. 2009; 150:889-896. [PubMed: 19176323]

190. Cardona-Gomez GP, Arango-Davila C, Gallego-Gomez JC, Barrera-Ocampo A, Pimienta H, Garcia-Segura LM. Estrogen dissociates Tau and alpha-amino-3-hydroxy-5-methylisoxazole-4propionic acid receptor subunit in postischemic hippocampus. Neuroreport. 2006; 17:1337-1341. [PubMed: 16951581]

191. Bae S, Zhang L. Gender Differences in Cardioprotection against Ischemia/Reperfusion Injury in Adult Rat Hearts: Focus on Akt and Protein Kinase C Signaling. Journal of Pharmacology and Experimental Therapeutics. 2005; 315:1125-1135. [PubMed: 16099927]

192. Morkuniene R, Arandarcikaite O, Ivanoviene L, Borutaite V. Estradiol-induced protection against ischemia-induced heart mitochondrial damage and caspase activation is mediated by protein kinase G. Biochim Biophys Acta.

193. Simpkins JW, Yang SH, Sarkar SN, Pearce V. Estrogen actions on mitochondria--physiological and pathological implications. Mol Cell Endocrinol. 2008; 290:51-59. [PubMed: 18571833]

194. Arnold S, Beyer C. Neuroprotection by estrogen in the brain: the mitochondrial compartment as presumed therapeutic target. J Neurochem. 2009; 110:1-11. [PubMed: 19457121]

195. Arevalo MA, Santos-Galindo M, Bellini MJ, Azcoitia I, Garcia-Segura LM. Actions of estrogens on glial cells: Implications for neuroprotection. Biochim Biophys Acta. 2009

196. Koerner IP, Zhang W, Cheng J, Parker S, Hurn PD, Alkayed NJ. Soluble epoxide hydrolase: regulation by estrogen and role in the inflammatory response to cerebral ischemia. Front Biosci. 2008; 13:2833-2841. [PubMed: 17981757]

197. Blasko E, Haskell CA, Leung S, Gualtieri G, Halks-Miller M, Mahmoudi M, Dennis MK, Prossnitz ER, Karpus WJ, Horuk R. Beneficial role of the GPR30 agonist G-1 in an animal model of multiple sclerosis. J Neuroimmunol. 2009; 214:67-77. [PubMed: 19664827]

198. Gould E, Tanapat P, Rydel T, Hastings N. Regulation of hippocampal neurogenesis in adulthood. Biol Psychiatry. 2000; 48:715-720. [PubMed: 11063968]

199. Hastings NB, Gould E. Rapid extension of axons into the CA3 region by adult-generated granule cells. J Comp Neurol. 1999; 413:146-154. [PubMed: 10464376]

200. Shioda, N.; Han, F.; Fukunaga, K.; Bagetta, GCMTSTaSS. International Review of Neurobiology. Academic Press; 2009. Chapter 26: Role of Akt and Erk Signaling in the Neurogenesis Following Brain Ischemia; p. 375-387.

201. Yamashima T, Tonchev AB, Borlongan CV. Differential response to ischemia in adjacent hippocampalsectors: neuronal death in CA1 versus neurogenesis in dentate gyrus. Biotechnology Journal. 2007; 2:596-607. [PubMed: 17345578]

202. Kokaia Z, Lindvall O. Neurogenesis after ischaemic brain insults. Curr Opin Neurobiol. 2003; 13:127-132. [PubMed: 12593991] 
203. Jin K, Minami M, Xie L, Sun Y, Mao XO, Wang Y, Simon RP, Greenberg DA. Ischemia-induced neurogenesis is preserved but reduced in the aged rodent brain. Aging Cell. 2004; 3:373-377. [PubMed: 15569354]

204. Galea LA, Uban KA, Epp JR, Brummelte S, Barha CK, Wilson WL, Lieblich SE, Pawluski JL. Endocrine regulation of cognition and neuroplasticity: our pursuit to unveil the complex interaction between hormones, the brain, and behaviour. Can J Exp Psychol. 2008; 62:247-260. [PubMed: 19071993]

205. Pawluski JL, Brummelte S, Barha CK, Crozier TM, Galea LA. Effects of steroid hormones on neurogenesis in the hippocampus of the adult female rodent during the estrous cycle, pregnancy, lactation and aging. Front Neuroendocrinol. 2009; 30:343-357. [PubMed: 19361542]

206. Perez-Martin M, Azcoitia I, Trejo JL, Sierra A, Garcia-Segura LM. An antagonist of estrogen receptors blocks the induction of adult neurogenesis by insulin-like growth factor-I in the dentate gyrus of adult female rat. Eur J Neurosci. 2003; 18:923-930. [PubMed: 12925018]

207. Saravia F, Revsin Y, Lux-Lantos V, Beauquis J, Homo-Delarche F, De Nicola AF. Oestradiol restores cell proliferation in dentate gyrus and subventricular zone of streptozotocin-diabetic mice. J Neuroendocrinol. 2004; 16:704-710. [PubMed: 15271063]

208. Saravia FE, Beauquis J, Revsin Y, Homo-Delarche F, de Kloet ER, De Nicola AF. Hippocampal neuropathology of diabetes mellitus is relieved by estrogen treatment. Cell Mol Neurobiol. 2006; 26:943-957. [PubMed: 16807785]

209. Calderone A, Jover T, Noh KM, Tanaka H, Yokota H, Lin Y, Grooms SY, Regis R, Bennett MV, Zukin RS. Ischemic insults derepress the gene silencer REST in neurons destined to die. $\mathrm{J}$ Neurosci. 2003; 23:2112-2121. [PubMed: 12657670]

210. Formisano L, Noh KM, Miyawaki T, Mashiko T, Bennett MV, Zukin RS. Ischemic insults promote epigenetic reprogramming of mu opioid receptor expression in hippocampal neurons. Proc Natl Acad Sci U S A. 2007; 104:4170-4175. [PubMed: 17360495]

211. Jung JE, Kim GS, Narasimhan P, Song YS, Chan PH. Regulation of Mn-superoxide dismutase activity and neuroprotection by STAT3 in mice after cerebral ischemia. J Neurosci. 2009; 29:7003-7014. [PubMed: 19474327]

212. Stapels M, Piper C, Yang T, Li M, Stowell C, Xiong ZG, Saugstad J, Simon RP, Geromanos S, Langridge J, Lan JQ, Zhou A. Polycomb group proteins as epigenetic mediators of neuroprotection in ischemic tolerance. Sci Signal. 2010; 3:ra15. [PubMed: 20197544]

213. Zukin RS. Eradicating the mediators of neuronal death with a fine-tooth comb. Sci Signal. 2010; 3:pe20. [PubMed: 20530801]

214. Longa EZ, Weinstein PR, Carlson S, Cummins R. Reversible middle cerebral artery occlusion without craniectomy in rats. Stroke. 1989; 20:84-91. [PubMed: 2643202] 


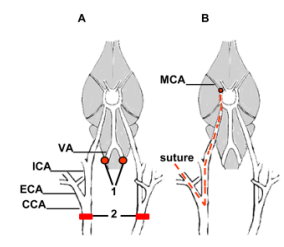

Figure 1.

Diagrams of the cerebrovascular anatomy of rats and methods for inducing global and focal ischemia.

(A) The permanent electrocauterization of the vertebral arteries (1) and the position of the surgical clips in the common carotid arteries (2) in a four-vessel occlusion (4-VO) model. Transient global ischemia is induced in a two-stage process. On day 1 , the vertebral arteries are coagulated (1). This procedure does not block cerebral blood flow but prevents collateral circulation to the forebrain during the carotid artery clamp on day 2 . Twenty-four hours after vertebral artery coagulation, transient global ischemia is induced by occluding the common carotid arteries (2) for $10 \mathrm{~min}$ followed by reperfusion. Sham-operated rats undergo vertebral artery coagulation and all other surgical procedures except for carotid artery occlusion. (B) An intraluminal suture is used for middle cerebral artery occlusion (MCAO) in the focal ischemia model. CCA, common carotid artery; ECA, external carotid artery; ICA, internal carotid artery; MCA, middle cerebral artery; VA, vertebral artery. Adapted from [214]. 

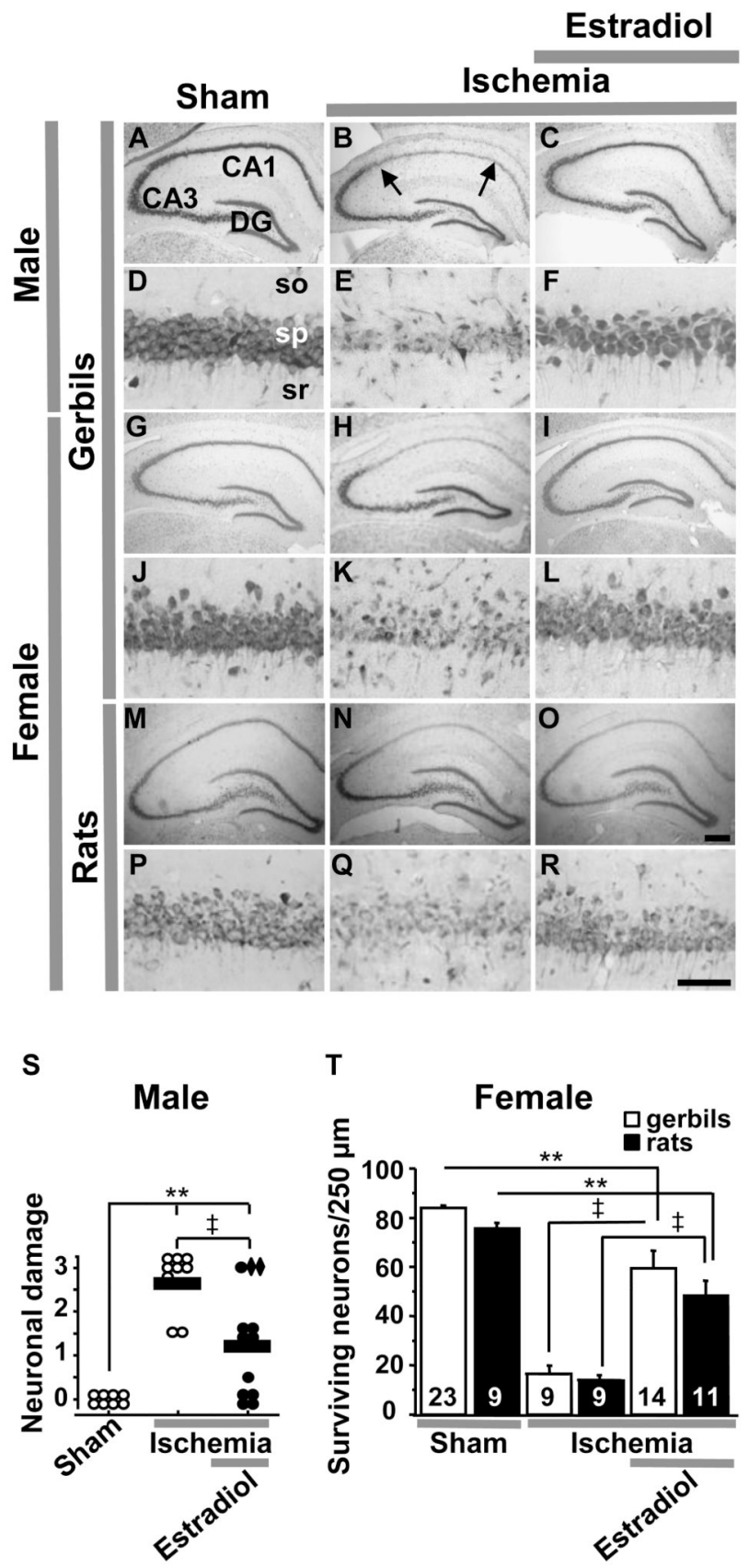

Figure 2.

Estradiol pretreatment affords neuroprotection against global ischemia-induced neuronal death in young males as well as females and in rats as well as gerbils.

Toluidine blue staining of coronal brain sections at the level of the dorsal hippocampus at 7 days after reperfusion from male gerbils $(\mathrm{A}-\mathrm{F})$, ovariectomized female gerbils $(\mathrm{G}-\mathrm{L})$ and ovariectomized female rats $(\mathrm{M}-\mathrm{R})$ treated with estradiol or placebo for 14 days and subjected to global ischemia or sham operation. Global ischemia induced significant cell loss in the CA1 pyramidal cell layer; little or no cell loss was apparent in CA3 or dentate gyrus (B, E, H, K, N,Q). Estradiol pretreatment for 14 days afforded significant neuroprotection against ischemia-induced damage $(\mathrm{C}, \mathrm{F}, \mathrm{I}, \mathrm{L}, \mathrm{O}, \mathrm{R})$. Hippocampal injury in 
male gerbils was assessed quantitatively by the grading scale of Pulsinelli and Brierley: $0=$ no neurons damaged; $1=$ a few $(<30 \%)$ neurons damaged; $2=$ many $(30-70 \%)$ neurons damaged; and $3=$ the majority of $(>70 \%)$ neurons damaged [38]. Neuronal damage scores from a minimum of four microscopic sections per animal were analyzed; comparisons among group means were made using ANOVA followed by Newman-Keuls test and plotted as scatter graphs (S). Neuronal damage scores from two hormone-treated gerbils with low plasma estradiol levels, indicating likely loss of the implanted pellet, are shown as diamonds. In female gerbils and rats, the number of surviving pyramidal neurons per 250$\mu \mathrm{m}$ length of the medial CA1 pyramidal cell layer was counted bilaterally in 4 sections per animal. The results were expressed as mean \pm SEM. Statistical comparisons were made between groups using ANOVA followed by Newman-Keuls test (T). DG, Dentate gyrus; so, stratum oriens; sp, stratum pyramidale; sr, stratum radiatum. Scale bars: lower magnification, $400 \mu \mathrm{m}$; higher magnification, $60 \mu \mathrm{m}$. **, $P<0.01 \mathrm{vs}$. sham; $\ddagger, P<0.01$ ischemia+estradiol $v s$. ischemia. Data from male gerbils are reproduced with permission from [45] Jover et al., J. Neurosci., March 15, 2002, 22 (6):2115-2124. Data from female gerbils and rats are reproduced with permission from [46] Jover-Mengual et al., Endocrinology 148 (2007) 1131-1143 (Copyright 2007, The Endocrine Society). 
A

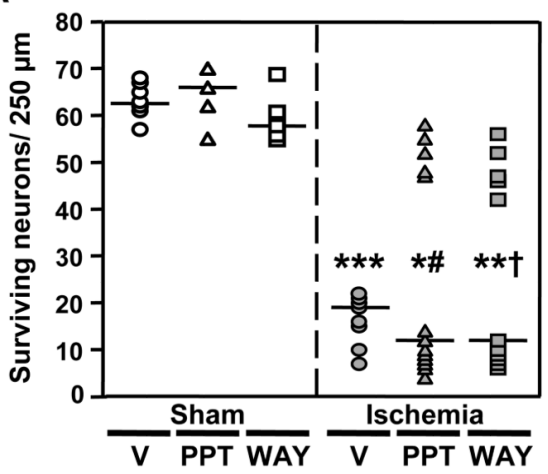

B

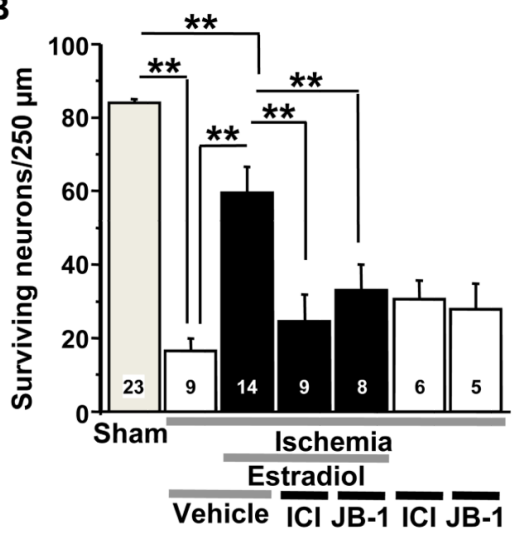

C

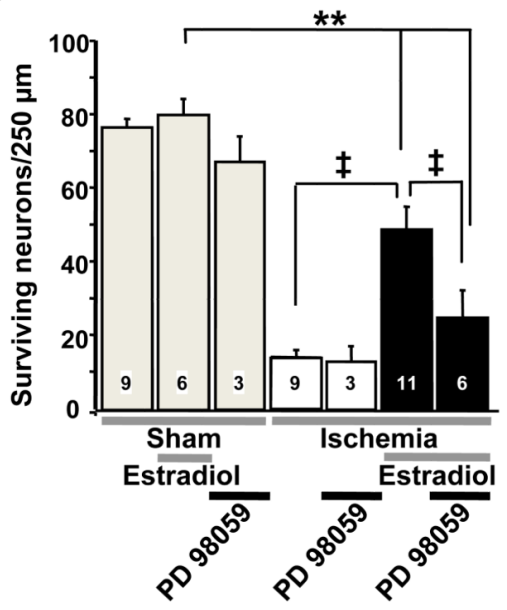

Figure 3.

Classical estrogen receptors (ER) and IGF1 receptors mediate neuroprotective actions of estradiol pretreatment.

(A) ER $\alpha$ (PPT) and ER $\beta$ (WAY) agonists elicit neuroprotection in some rats after global ischemia. Rats were injected daily with vehicle (V), PPT or WAY for 14 days prior to undergoing global ischemia or sham surgery. Hormonal treatments were continued until rats were euthanized 7 days after ischemia or sham operation. Sham operated rats are represented by open symbols, and ischemic rats are represented by filled symbols. The median number of surviving pyramidal cells for each treatment group is demonstrated by a horizontal line, and differences between groups were analyzed by Fisher's exact test. 
(Ischemia $+\mathrm{V} v s$. Sham $+\mathrm{V}$, ${ }^{* * *} P<0.001$; PPT+Ischemia $v s$. PPT+Sham, $* P<0.04$; WAY + Ischemia $v s$. WAY+Sham, $* * P<0.02$ ). Differences in the number of rats per group with more than 40 surviving neurons after drug treatment and ischemia were analyzed using Chi square (WAY+Ischemia $v s$. V+Ischemia, $\dagger, P=0.04$; PPT+Ischemia $v s$. V+Ischemia, \#, $P=$ $0.05)$. Data are reproduced with permission from [47] Miller et al., Endocrinology 146 (2005) 3070-3079 (Copyright 2005, The Endocrine Society).

(B) The ER antagonist ICI 182,780 and IGF1 receptor antagonist JB-1 block estradiol protection. Ovariectomized female gerbils were treated with estradiol or placebo for 14 days and subjected to global ischemia or sham operation. Animals received icv infusions of ICI 182,780, JB- 1 or vehicle after ischemia. ICI 182,780 and JB-1 did not affect neuronal survival in ischemic (two rightmost bars), but greatly reduced estradiol protection, assessed at 7 days after surgery. Neither vehicle significantly altered neuronal survival $v s$. no treatment in placebo- or estradiol-treated animals subjected to sham operation. Therefore, vehicle and control data were pooled for purposes of illustration (grey bar labeled "sham"). Similarly, neither vehicle significantly altered neuronal survival $v s$. no treatment in placebotreated animals subjected to global ischemia. Thus, these data were also pooled (white bar labeled "ischemia+vehicle"). (**, $P<0.01)$. Data are reproduced with permission from [46] Jover-Mengual et al., Endocrinology 148 (2007) 1131-1143 (Copyright 2007, The Endocrine Society).

(C) The ERK/MAP kinase inhibitor PD98059 attenuates estradiol protection.

Ovariectomized female rats were treated with estradiol or placebo and subjected to global ischemia (white and black bars) or sham operation (grey bars) as described above. Animals received PD98059 $(3 \mu \mathrm{g})$ or vehicle (10\% DMSO) icv at 0 and $12 \mathrm{~h}$ after ischemia.

PD98059 greatly reduced estradiol protection, assessed at 7 days after surgery. $* *, P<0.01$ vs. all sham groups; $\ddagger, P<0.01$ ischemia+estradiol $v s$. ischemia or ischemia+estradiol +PD98059. Data are reproduced with permission from [46] Jover-Mengual et al., Endocrinology 148 (2007) 1131-1143 (Copyright 2007, The Endocrine Society). 


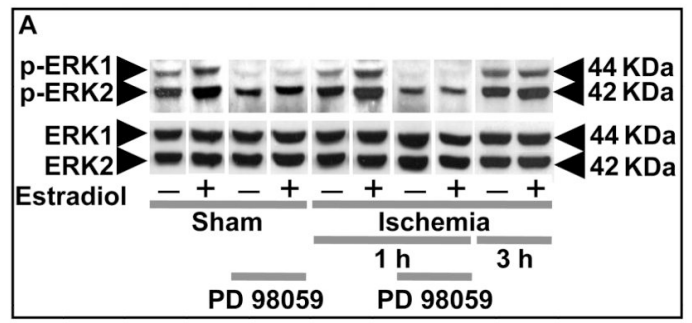

B
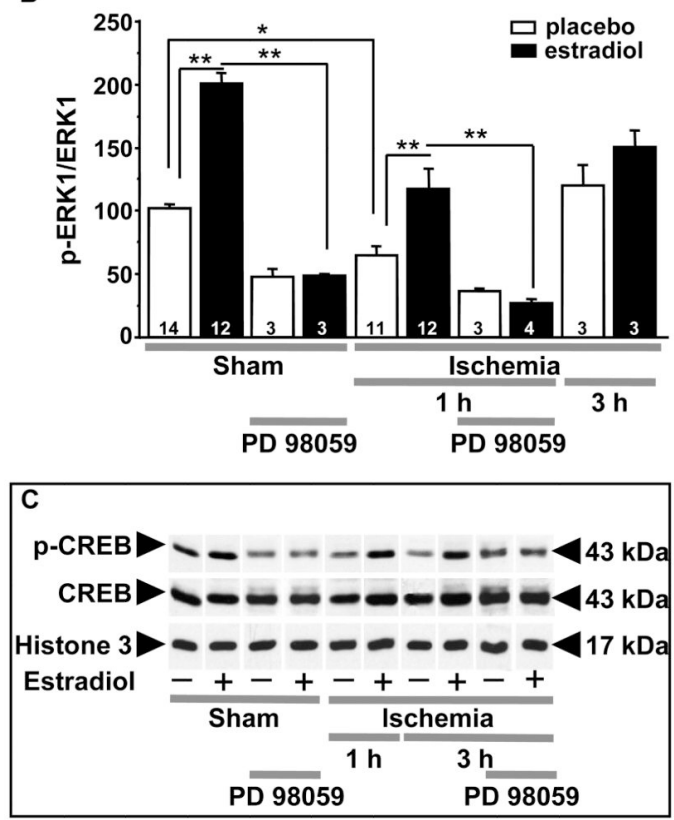

D

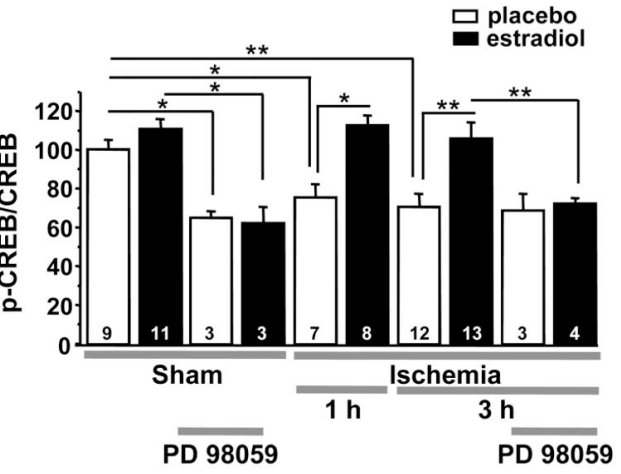

Figure 4.

Estradiol pretreatment rescues CA1 pyramidal neurons by activation of ERK/MAPK signaling and maintenance of $\mathrm{p}-\mathrm{CREB}$.

$(\mathrm{A}, \mathrm{B})$. Estradiol prevents ischemia-induced dephosphorylation of ERK1 in CA1.

Representative Western blots (A) and relative abundance of p-ERK1 (B) in CA1 whole-cell lysates from placebo- and estradiol-treated rats subjected to sham surgery or ischemia at 1 and $3 \mathrm{~h}$ after surgery. Subsets of animals were injected with PD98059 at $0 \mathrm{~h}$ and sacrificed at $1 \mathrm{~h}$ after surgery. Westerns were probed with antibodies to p-ERK1/2 and ERK1/2. Ischemia induced dephosphorylation of ERK1 (A, B). Estradiol significantly enhanced ERK1 phosphorylation in shams and maintained levels of p-ERK1 in ischemic rats (B). 
PD98059 blocked the estradiol-induced increase in phosphorylation of ERK1 $(A, B)$ in control (sham) CA1. PD98059 also reversed the ability of estradiol to maintain ERK1 phosphorylation in post-ischemic CA1 (A,B). Values for ischemic rats were normalized to the corresponding sham value. ${ }^{*}, P<0.05 ;{ }^{* *}, P<0.01$.

(C,D.) Estradiol acts via MAPK signaling to prevent ischemia-induced CREB dephosphorylation. Representative Western blots (C) and relative p-CREB abundance (D) in the nuclear fraction of CA1 of placebo- and estradiol-treated rats subjected to sham operation or ischemia at 1 and $3 \mathrm{~h}$ after surgery. Subsets of animals were injected with PD98059 at $0 \mathrm{~h}$ and sacrificed at $3 \mathrm{~h}$ after surgery. Westerns were probed with antibodies to p-CREB, CREB and histone 3 (nuclear marker). Ischemia promoted dephosphorylation of CREB in the nuclei of CA1 neurons. Estradiol maintained the phosphorylated, activated state of CREB in the CA1 of ischemic rats. PD98059 blocked the ability of estradiol to maintain p-CREB levels in post-ischemic CA1. Values for experimental animals were normalized to the corresponding sham value. **, $P<0.01$. $^{*} P<0.05$.

Data are reproduced with permission from [46] Jover-Mengual et al., Endocrinology 148 (2007) 1131-1143 (Copyright 2007, The Endocrine Society). 


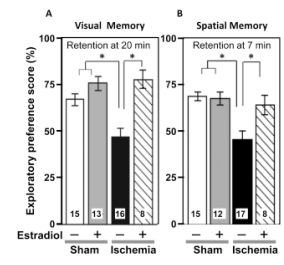

Figure 5.

Estradiol pretreatment improves visual and spatial recognition memory performance in young females rats subjected to global ischemia.

(A) Visual working memory was assessed by the object recognition task. Data are reported as the exploratory preference score (novel object exploration / total object exploration, \%; X \pm SEM) for 3-min trials. At the 20 min retention interval, ischemic rats (Ischemia) exhibit significantly impaired visual memory relative to sham-operated control rats (Sham).

Estradiol does not alter visual recognition memory scores in sham rats (Estradiol + Sham), but reverses memory deficits in ischemic rats (Estradiol + Ischemia).

(B) Spatial working memory was assessed by the object placement task. Data are reported as the exploratory preference score (displaced object exploration / total object exploration, \%;

$\mathrm{X} \pm \mathrm{SEM}$ ) for 3-min trials. At the $7 \mathrm{~min}$ retention interval, ischemic rats (Ischemia) show impaired spatial memory relative to sham-operated rats (Sham). Chronic estradiol does not significantly alter spatial working memory scores in sham rats (Estradiol + Sham), but reverses the memory deficits in ischemic rats (Estradiol + Ischemia).

*, $P<0.05$. Samples sizes are indicated within the bars.

Data are reproduced with permission from [87] Gulinello et al., Horm Behav 49 (2006) 246260. 


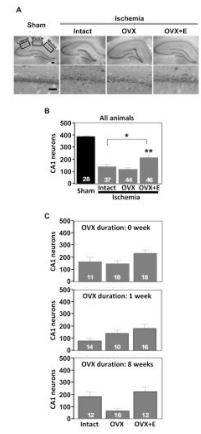

Figure 6.

Estradiol pretreatment reduces CA1 pyramidal cell loss in OVX, middle-aged females after global ischemia.

Estradiol was provided for 2 weeks before ischemia or sham surgery as a timed-release pellet as in Figures 2-5.

(A) Representative photomicrographs from the 1 week OVX interval of intact, OVX, and OVX+estradiol (E) middle-aged female rats subjected to global ischemia or sham surgery. At 12 days after reperfusion, viable neurons in 4 hematoxylin and eosin-stained sections containing the dorsal hippocampal CA1 were counted in 3 sectors (lateral, middle, and medial). Scale bars, Lower magnification (4x), $400 \mu \mathrm{m}$; higher magnification (40x), $60 \mu \mathrm{m}$. (B) Data represent a grand sum across the 3 counting sectors and over right and left hemispheres. Because no statistical difference was found among the different sham groups (intact, OVX, OVX+E) at 1 and $8 \mathrm{wk}$ after OVX, these animals were pooled into one sham group. Global ischemia induced CA1 cell loss $v s$. sham-operated animals. Treatment with E significantly increased CA1 cell survival. $*, P<0.01$ compared to sham-operated rats, $* *, P$ $<0.01$ compared to intact and OVX rats.

(C) The data from ischemic animals in panel B presented for each OVX duration. There was no significant impact of OVX duration on CA1 cell survival or estradiol protection in middle-aged females subjected to transient global ischemia (10 $\mathrm{min})$.

Data are reproduced with permission from [140] De Butte-Smith et al., Horm Behav 55 (2009) 442-453. 


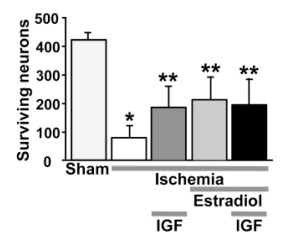

Figure 7.

Estradiol and IGF1 pretreatment provide significant protection against CA1 cell loss caused by global ischemia in middle-aged females subjected to prolonged hormone withdrawal ( 8 weeks OVX).

Estradiol was provided as a timed-release pellet as in Figures 2-5, and IGF1 was infused icv using osmotic minipumps (see [150] for details). Viable neurons were counted in 3 sectors (lateral, middle, and medial) in four hematoxylin and eosin stained sections of the dorsal hippocampus. Data represent the grand sum (mean \pm SD) of three counting sectors over both the right and left hemispheres. Estradiol and IGF1 alone provided equivalent neuroprotection, and their effects were not additive. ${ }^{*}$ Significantly less than sham-operated animals $(P<0.001)$. **Significantly greater than vehicle-treated ischemic animals $(P<$ $0.001)$.

Data are reproduced with permission from [150] Traub et al., J Neuroendocrinol 21 (2009) 1038-1044. 
A

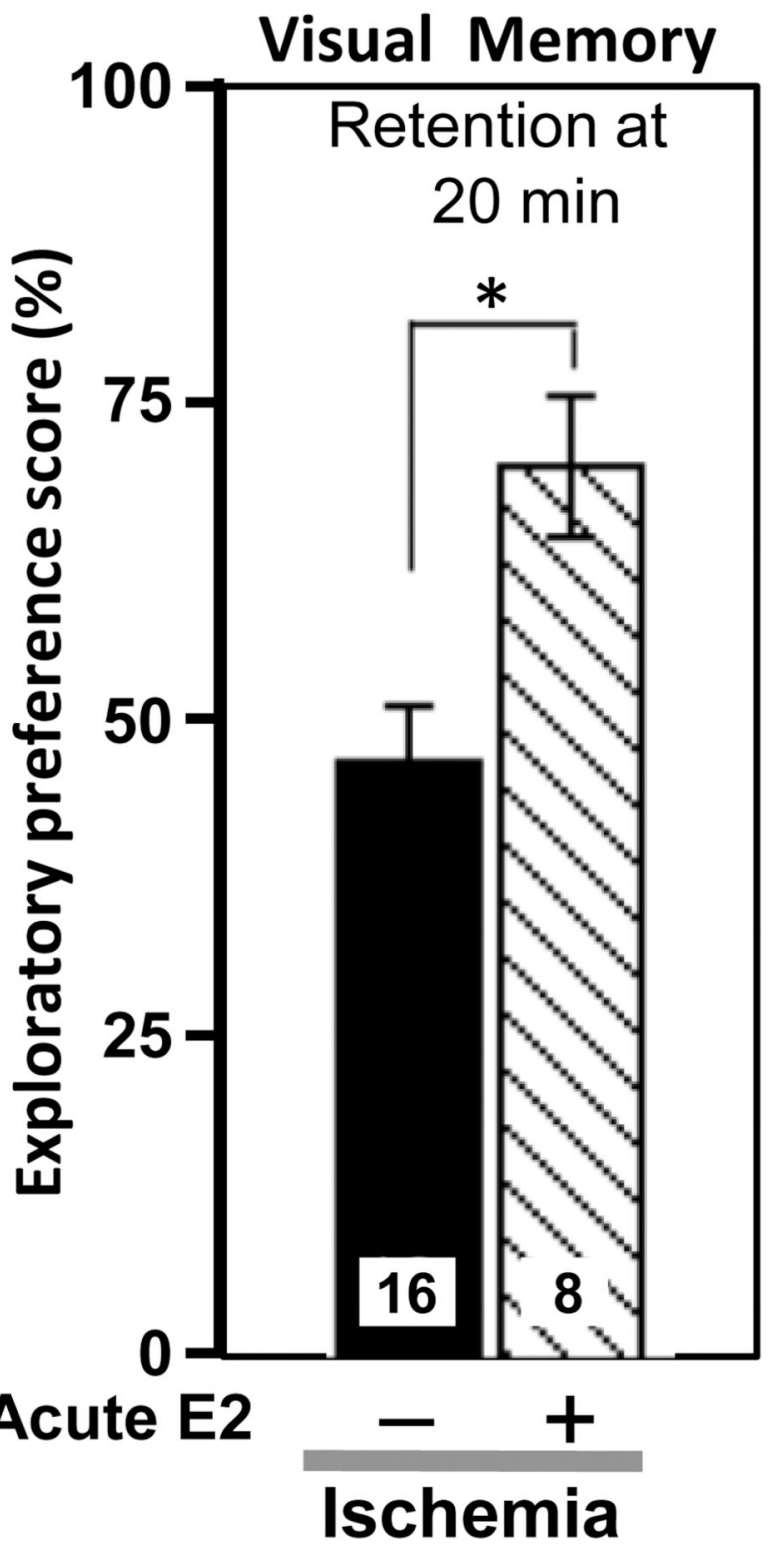

B

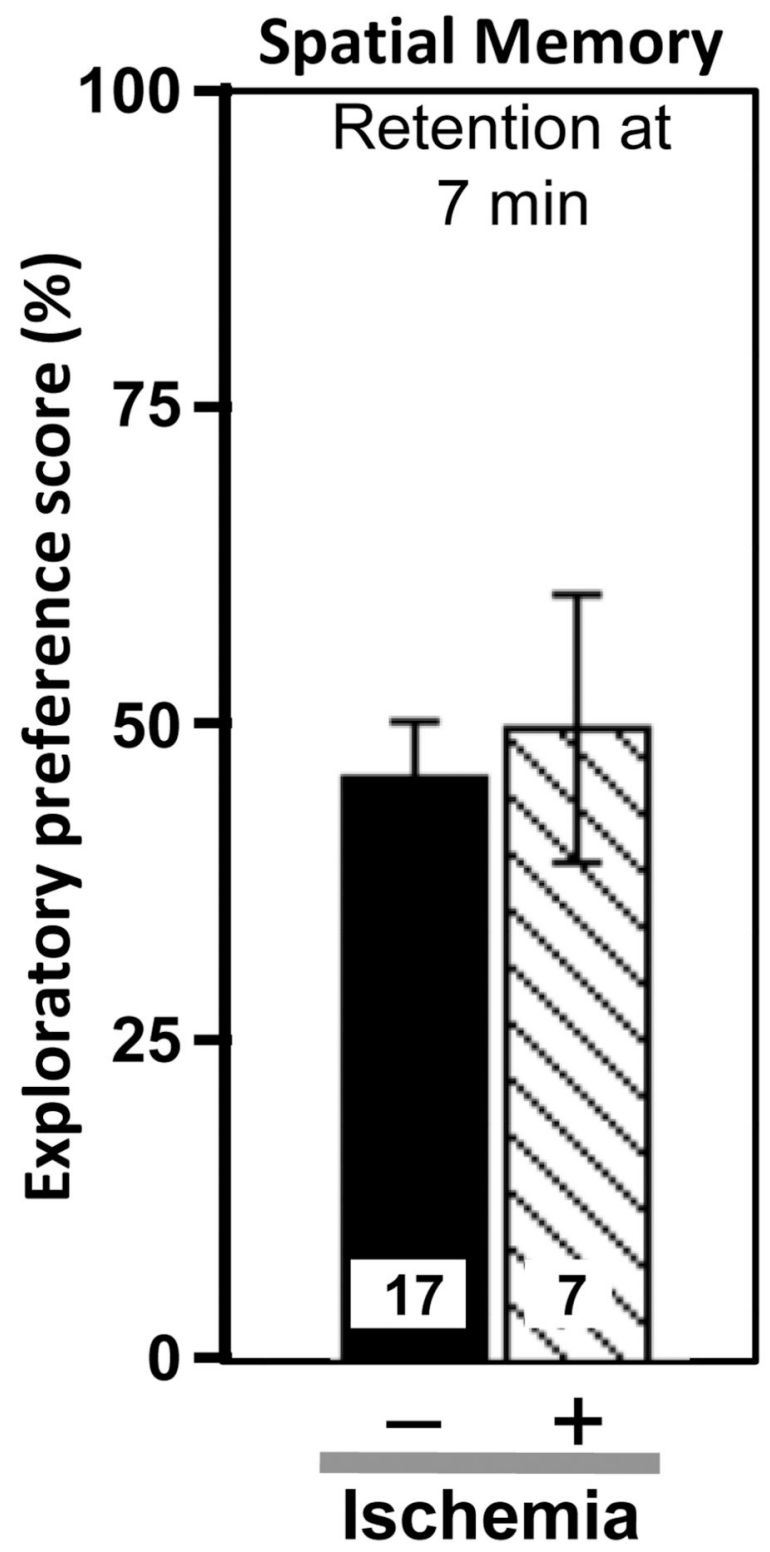

Figure 8.

Estradiol administered immediately after ischemia improves visual but not spatial recognition memory performance in young females rats subjected to global ischemia.

(A) Visual recognition memory scores at a 20 min retention interval.

(B) Spatial recognition memory scores at a 7 min retention interval.

Data are reported as the exploratory preference score as defined in Fig. 5.

$*, P<0.05$. Sample sizes are denoted on individual bars.

Data are reproduced with permission from [87] Gulinello et al., Horm Behav 49 (2006) 246260. 


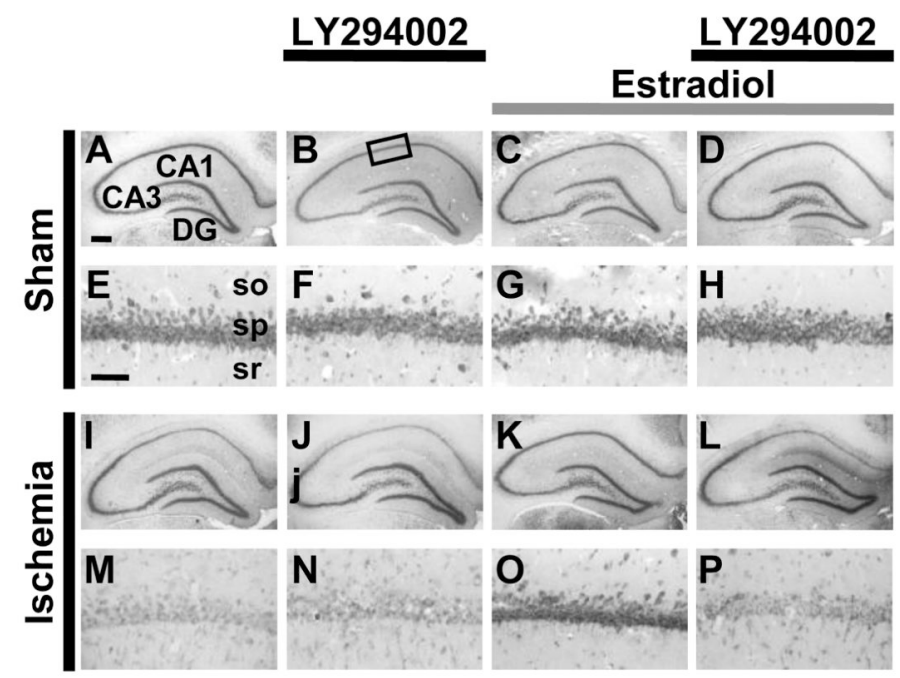

Q

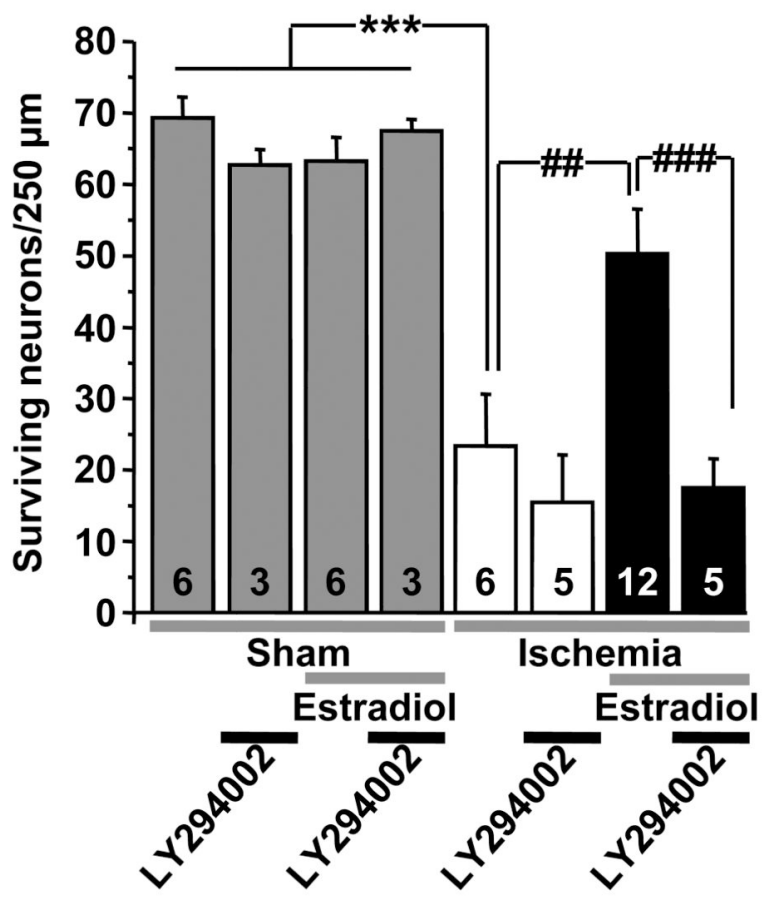

Figure 9.

The PI3K inhibitor LY294002 attenuates acute estradiol protection. Ovariectomized female rats were subjected to global ischemia (white and black bars) or sham operation (grey bars) and infused icv with estradiol or vehicle immediately upon reperfusion. Animals also received LY294002 or vehicle icv at 0 and $12 \mathrm{~h}$ after vehicle or estradiol injection. Global ischemia induced extensive death of pyramidal cells in the hippocampal CA1 at 7 days postischemia (I, M, J, N, Q), and estradiol significantly reduced neuronal death $(\mathrm{K}, \mathrm{O}, \mathrm{Q})$. LY294002 reversed estradiol protection, assessed at 7 days after surgery (L, P, Q). Scale bars: lower magnification, $400 \mu \mathrm{m}$; higher magnification, $40 \mu \mathrm{m}$. so, stratum oriens; sp, stratum pyramidale; sr, stratum radiatum. 
***, $P<0.001$ vs. all sham groups; ${ }^{\# \#}, P<0.01$ ischemia+estradiol vs. ischemia and ${ }^{\# \#}, P$ $<0.001$ vs. ischemia + estradiol + LY294002.

Data are reproduced with permission from [154] Jover-Mengual et al., Brain Res 1321 (2010) 1-12. 


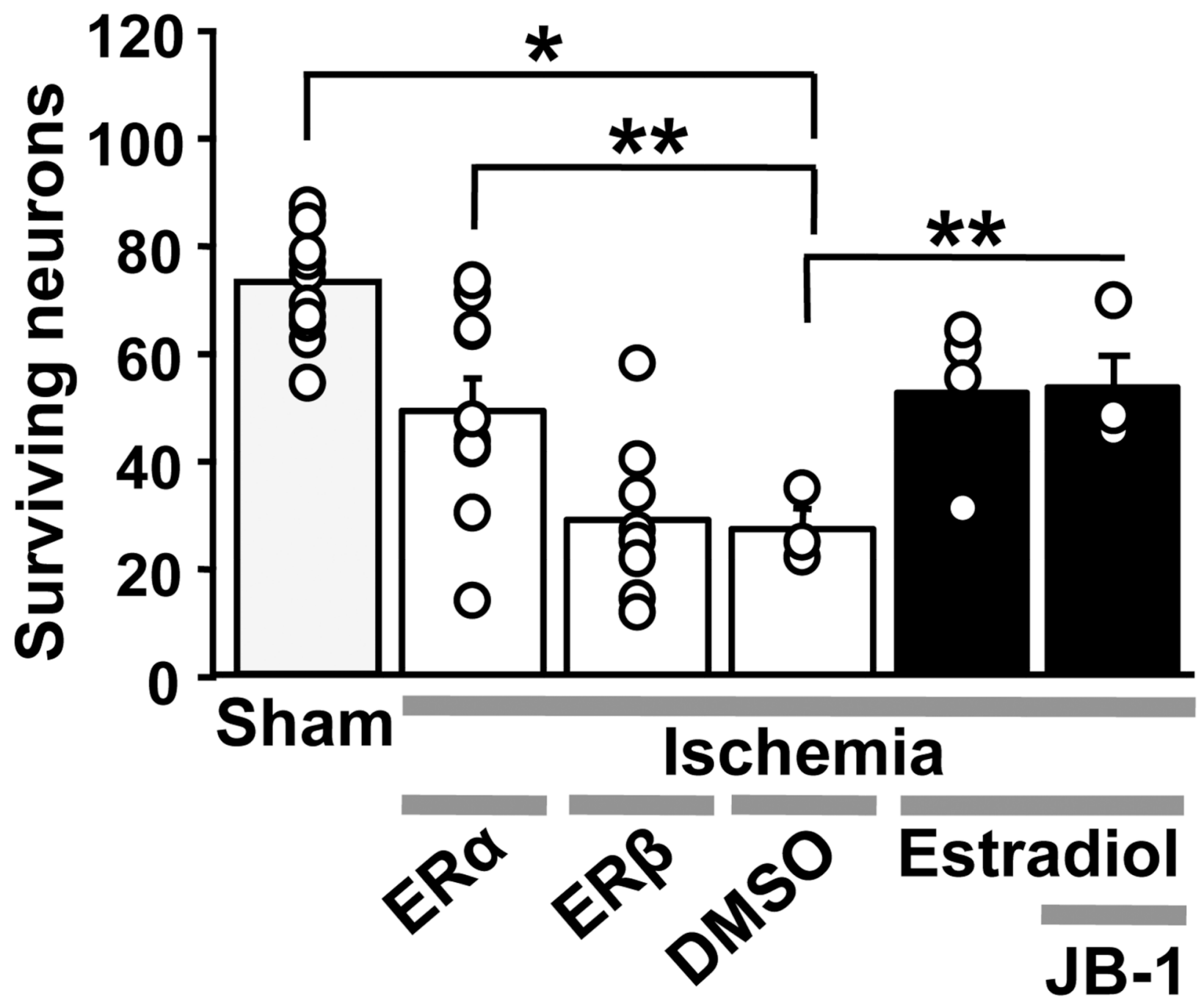

Figure 10.

Acute administration of an ER $\alpha$ selective agonist mimics the actions of estradiol. Young female rats were ovariectomized for 1 week, subjected to global ischemia or sham operation, and infused icv with the indicated agents immediately upon reperfusion. Ischemic control females were infused with vehicle only (DMSO). Estradiol $(2.2 \mu \mathrm{g})$ and the ER $\alpha$ agonist $16 \alpha-\mathrm{LE}_{2}(50 \mu \mathrm{g})$ significantly reduced CA1 cell death, but the ER $\beta$ agonist $8 \beta-\mathrm{VE}_{2}(50 \mu \mathrm{g})$ did not. The IGF1 receptor antagonist JB1 did not reverse estradiol protection. ${ }^{*} P<0.01$; $* * P<0.05$. 


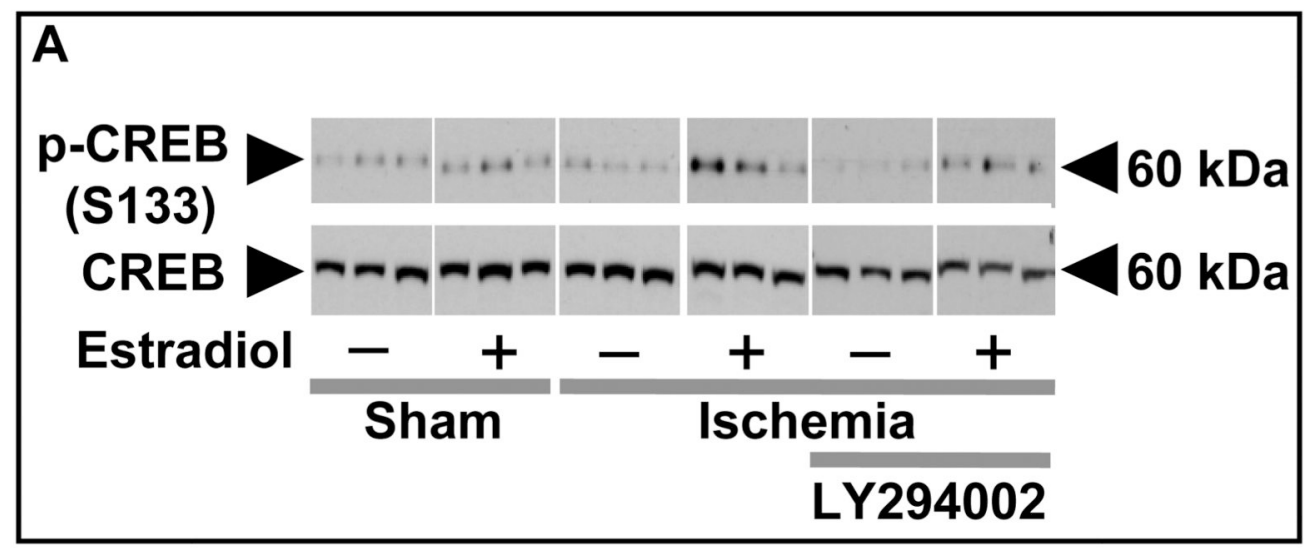

B

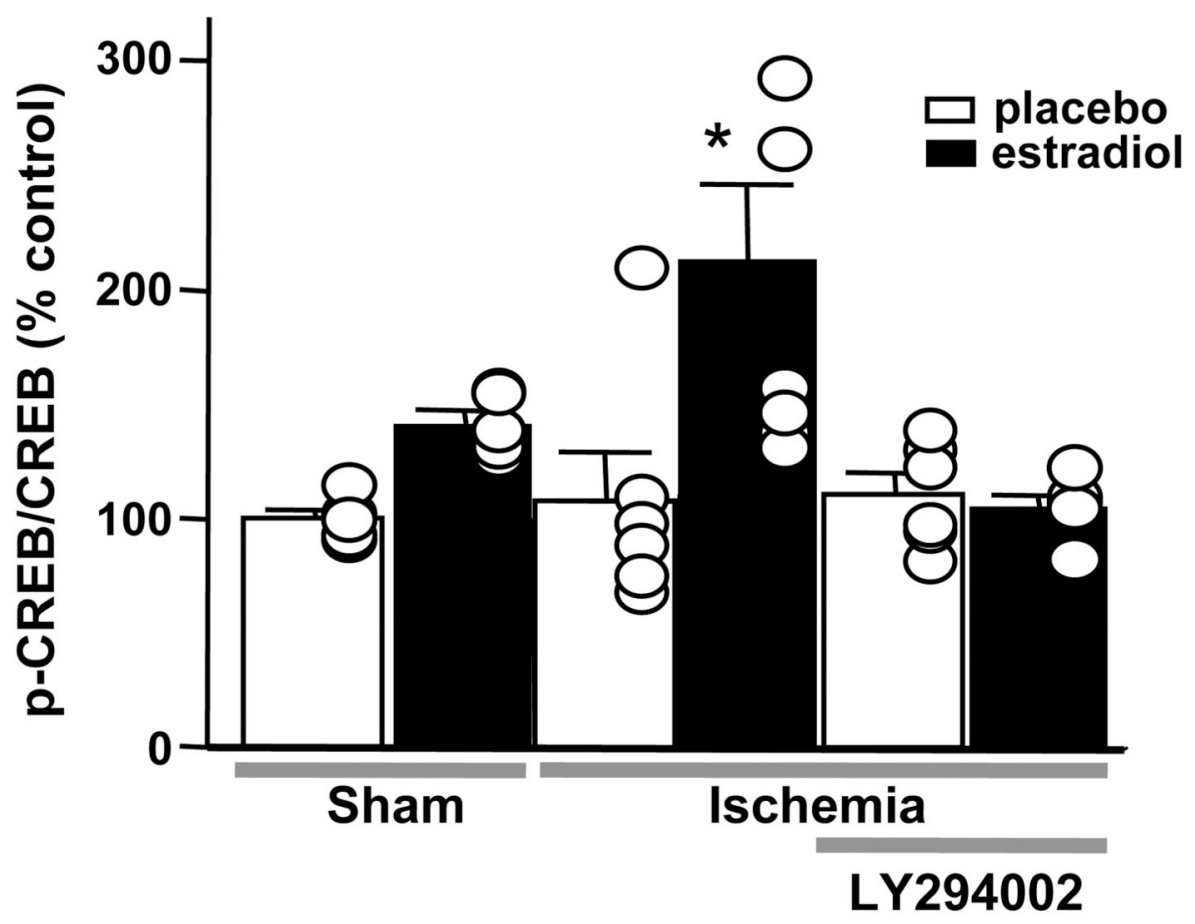

Figure 11.

Estradiol administered acutely after global ischemia acts via PI3K signaling to maintain CREB activation.

Ovariectomized female rats were subjected to global ischemia or sham operation and treated with estradiol $(2.2 \mu \mathrm{g})$ or vehicle immediately upon reperfusion. Subsets of animals were injected with LY294002 immediately after estradiol or vehicle and killed $3 \mathrm{~h}$ after surgery. Westerns were probed with antibodies to p-CREB and CREB.

(A) Representative Western blots of p-CREB and CREB in the nuclear fraction of CA1 of vehicle- and estradiol-injected rats subjected to sham operation or ischemia and LY294002. 
(B) Quantification of relative p-CREB abundance at $3 \mathrm{~h}$ after ischemia. Estradiol maintained the phosphorylated, activated state of CREB in the CA1 of ischemic rats. LY294002

blocked the ability of estradiol to maintain p-CREB levels in post-ischemic CA1. Values for experimental animals were normalized to the corresponding sham value. $* P<0.05$ vs all other groups, 


\section{A}
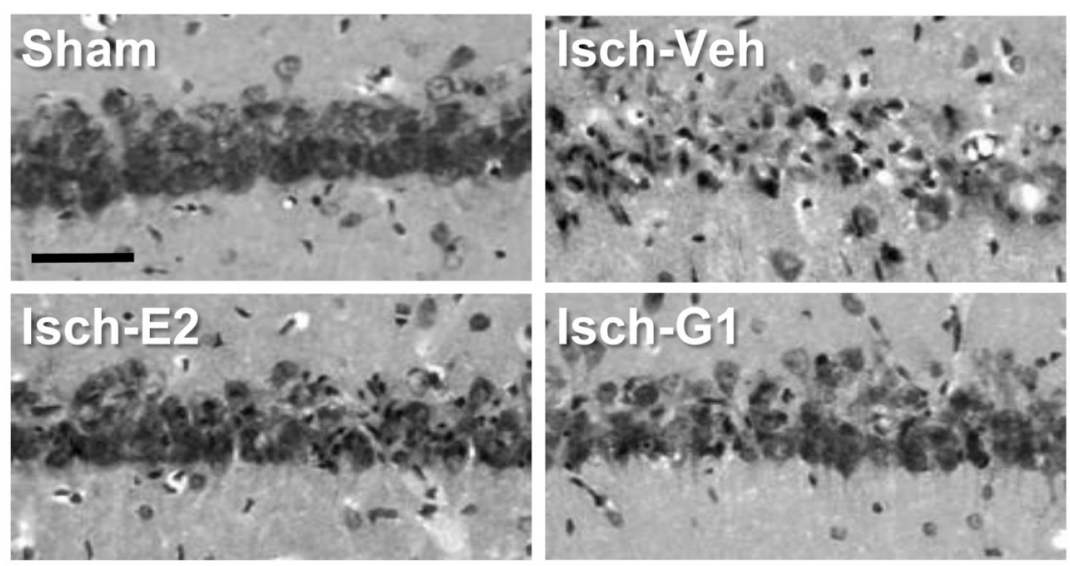

B

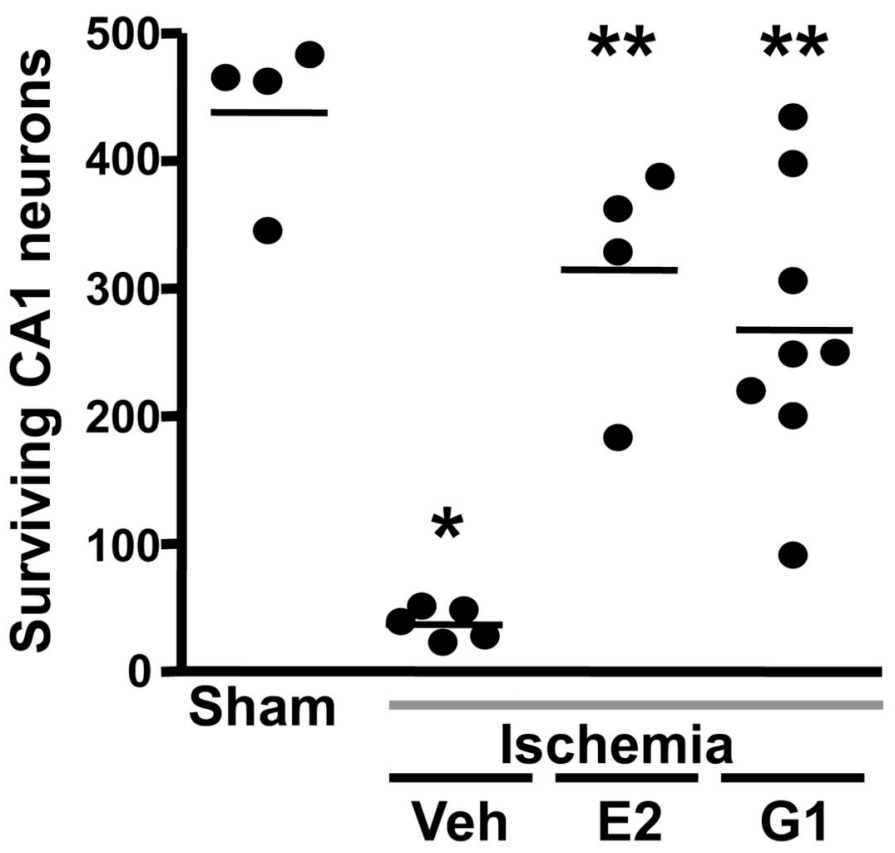

Figure 12.

The selective GPR30 agonist G1 affords neuroprotection when administered to young rats immediately after ischemia.

(A) Representative photomicrographs of hippocampal neurons in the dorsal CA1 region 7 days after sham surgery or global ischemia (Isch) in young adult female rats that were OVX for 1 week and injected icv with either estradiol (E2; $2.2 \mu \mathrm{g})$, G1 $(50 \mu \mathrm{g})$ or vehicle (DMSO) immediately after ischemia. Scale bars: low magnification, $400 \mu \mathrm{m}$; higher magnification, $60 \mu \mathrm{m}$.

(B) Quantification of living pyramidal neurons in the CA1 region of the hippocampus 7 days after ischemia. Neurons were counted in 3 sectors (lateral, middle and medial) of the dorsal 
hippocampus. $* P<0.001 v s$. sham, $* * P<0.001 v s$. ischemia/vehicle. Data are reproduced from [181] Lebesgue et al., PLoS One 5 (2010) e8642. 


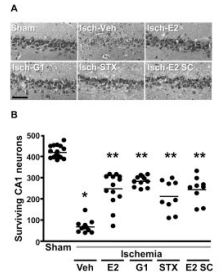

\section{Figure 13.}

Estradiol (E2), the selective GPR30 agonist G1 and STX are neuroprotective when administered immediately after ischemia in middle-aged female rats deprived of ovarian hormones for 8 weeks.

(A) Representative photomicrographs of hippocampal neurons in the dorsal CA1 region 7 days after sham surgery or global ischemia in animals injected icv immediately after reperfusion with either vehicle, E2 $(2.2 \mu \mathrm{g}), \mathrm{G} 1(50 \mu \mathrm{g})$, STX $(50 \mu \mathrm{g})$ or vehicle. Additional animals were injected sc with E2 $(100 \mu \mathrm{g} / \mathrm{kg})$. Scale bars: low magnification, $400 \mathrm{~mm}$; higher magnification, $60 \mathrm{~mm}$.

(B) Quantification of living pyramidal neurons in the CA1 region of the hippocampus 7 days after ischemia. Neurons were counted in 3 sectors (lateral, middle and medial) of the dorsal hippocampus. $* P<0.001$ vs. sham, $* * P<0.001 v s$. ischemia/vehicle.

Data are reproduced from [181] Lebesgue et al., PLoS One 5 (2010) e8642. 